\title{
Dclk1 distinguishes between tumor and normal stem cells in the intestine
}

\section{$\operatorname{AUTHOR}(\mathrm{S})$ :}

Nakanishi, Yuki; Seno, Hiroshi; Fukuoka, Ayumi; Ueo, Taro; Yamaga, Yuichi; Maruno, Takahisa; Nakanishi, Naoko; ... Taketo, Makoto M; Yonehara, Shin; Chiba, Tsutomu

\section{CITATION:}

Nakanishi, Yuki ...[et al]. Dclk1 distinguishes between tumor and normal stem cells in the intestine. Nature Genetics 2012, 45(1): 98-103

\section{ISSUE DATE:}

2012-12-02

URL:

http://hdl.handle.net/2433/163077

\section{RIGHT:}

(C) 2012 Nature Publishing Group, a division of Macmillan Publishers Limited. All Rights Reserved.; 許諾条件により本文は2013-06-02に公開.; この論文は出版社版でありません。 引用の際には出版社版をご確認ご利用ください。; This is not the published version. Please cite only the published version. 
Dclk1 distinguishes between tumor and normal stem cells in the intestine

Yuki Nakanishi ${ }^{1}$, Hiroshi Seno ${ }^{1}$, Ayumi Fukuoka ${ }^{2}$, Taro Ueo ${ }^{1}$, Yuichi Yamaga $^{1}$, Takahisa Maruno ${ }^{1}$, Naoko Nakanishi ${ }^{1}$, Keitaro Kanda ${ }^{1}$, Hideyuki Komekado $^{1}$, Mayumi Kawada ${ }^{1}$, Akihiro Isomura ${ }^{3}$, Kenji Kawada ${ }^{4}$, Yoshiharu Sakai $^{4}$, Motoko Yanagita ${ }^{5}$, Ryoichiro Kageyama ${ }^{3}$, Yoshiya Kawaguchi ${ }^{6}$, Makoto M. Taketo ${ }^{7}$, Shin Yonehara ${ }^{2}$, Tsutomu Chiba ${ }^{1}$

${ }^{1}$ Department of Gastroenterology and Hepatology, Kyoto University Graduate School of Medicine, Kyoto, Japan. 'Laboratory of Molecular and Cellular Biology, Graduate School of Biostudies, Kyoto University, Kyoto, Japan. ${ }^{3}$ Institute for Virus Research, Kyoto University, Kyoto, Japan. ${ }^{4}$ Department of Surgery, Kyoto University Graduate School of Medicine, Kyoto, Japan. ${ }^{5}$ Department of Nephrology, Kyoto University Graduate School of Medicine, Kyoto, Japan. ${ }^{6}$ Department of Clinical Application, Center for iPS Cell Research and Application, Kyoto University, Kyoto, Japan. ${ }^{7}$ Department of Pharmacology, Kyoto University Graduate School of Medicine, Kyoto, Japan

Correspondence should be addressed to H.S. (seno@kuhp.kyoto-u.ac.jp)

Keywords:

tumor initiating cell, cancer stem cell, lineage tracing, colon cancer, Dcamkl1 


\section{Introductory paragraph}

Many investigators have generated great interest in tumor stem cells (TSCs) as therapeutic targets; however, cancer therapies targeting TSCs are limited. A drawback is that TSC markers are often shared by normal stem cells (NSCs) ${ }^{1-4}$, and thus, therapies that target these markers may cause severe injury to normal tissues.

To identify a TSC-specific marker, we focused on doublecortin-like kinase 1 (Dclk1). Dclk1 was reported as a candidate NSC marker in the gut ${ }^{5,6}$, but recent reports have suggested it as a marker of differentiated cells (e.g., Tuft cells) ${ }^{7,8}$.

By lineage tracing experiments, we here revealed that Dclk1 does not mark NSCs in the intestine but it marks TSCs that continuously produce tumor progeny in the polyps of $A p c^{\text {Min/+ }}$ mice. Specific ablation of Dclk1 ${ }^{+}$TSCs resulted in a dramatic regression of polyps without apparent damage to the normal intestine. Our data demonstrate the potential of a therapy for colorectal cancer (CRC) based on targeting Dclk1 ${ }^{+}$TSCs.

\section{Main body}

Recent advances in stem cell biology have identified intestinal NSC markers, such as Lgr5, Bmi1, and CD133 $3^{3,9,10}$. Accumulating evidence also supports the existence of TSCs ${ }^{1,2,11-16}$, which resemble NSCs in their capacity for self-renewal and continuously replenishing tumor progeny ${ }^{17,18}$. Previously reported TSC markers are shared by NSCs in the intestine ${ }^{1-4}$; thus, identifying TSC-specific markers is an important challenge.

Dclk1 was reported as a putative intestinal NSC marker located at the "+4 position," just above the Paneth cells ${ }^{5,6,19}$. However, recent reports have suggested that Dclk1 marks Tuft cells ${ }^{7,8}$, and it remains unclear whether Dclk1 marks NSCs. Furthermore, the presence of Dclk $1^{+}$cells in murine intestinal tumors and human CRCs has been reported ${ }^{6,20}$; however, their potential capacity for tumorigenesis remains also unknown.

In this study, we confirmed that Dclk1 ${ }^{+}$cells were scattered in the intestinal epithelium, but were most frequently observed at the lower crypt in normal murine and human intestines as previously reported ${ }^{6,19}$ (Supplementary Fig. 1a, 
b, d). Dclk1 ${ }^{+}$cells were also scattered in the intestinal polyps of $A p c^{\mathrm{Min} /+}$ mice and human CRCs (Supplementary Fig. 1c, e-h).

To investigate the stemness of Dclk $1^{+}$cells in normal intestines and during intestinal tumorigenesis, we generated knock-in mice by integrating a creERT2-IRES-EGFP cassette at the first ATG codon of Dclk1 (Dclk1 $1^{\text {creERT2/+; }}$

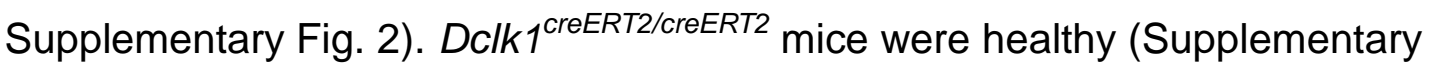
Fig. 3), in accordance with a previous report ${ }^{21}$. As reported ${ }^{6,20}$, Dclk1 $^{+}$cells were distinct from other epithelial cell populations (Supplementary Fig. 4).

To test whether Dclk1 marks NSCs in the normal intestine, we performed tamoxifen/cre-mediated lineage tracing ${ }^{22,23}$ in the small intestine (Fig. 1a) and colon (Supplementary Fig. 5) of Dclk1 $1^{\text {creERT2/+; }}$ Rosa26R mice. No LacZ-labeled cells were detected in the absence of tamoxifen injection (data not shown). One day after injection, scattered LacZ-labeled blue cells were found most frequently at the lower crypt, in accordance with our immunohistochemical data (Fig. 1b-d). However, majority of blue cells shifted toward the villus tip on a daily basis, which was accompanied by a decrease in their numbers (Fig. 1b-e). These data suggest that most Dclk1 ${ }^{+}$cells originated at the lower crypt, migrated upward, and disappeared around the villus tip within a few weeks. We could not detect BrdU incorporation in Dclk1 $1^{+}$cells in the normal intestine (Fig. 1f, g). Collectively, it is suggested that Dclk1 was not a NSC marker in the normal intestine.

Subsequently, we tested the potential stemness of Dclk $1^{+}$cells during regeneration after mucosal injury induced by irradiation or dextran sulfate sodium treatment (Supplementary Fig. 6). We found that an extremely small number of "blue stripes" comprised LacZ-labeled Dclk1-positive cell lineages in each experiment. Thus, Dclk1 ${ }^{+}$cells rarely produced progeny during mucosal regeneration, and their potential stemness was strictly limited.

We then investigated whether Dclk1 marks intestinal TSCs. Surprisingly, lineage tracing analyses of $D c l k 1^{\text {creERT2/+}}$; Rosa26R; $A p c^{\mathrm{Min} /+}$ mice demonstrated that polyps were occupied by LacZ-labeled blue cells ("blue polyps"), with scattered LacZ expression in the normal intestine 7 days after tamoxifen injection (Fig. 2a-d, Supplementary Fig. 7). This finding highlighted a unique character of Dclk1-expressing cells when compared with the results of knock-in 
mice using $L g r 5$, a representative intestinal NSC and TSC marker ${ }^{4,9,24}$. In Lgr5-EGFP-IRES-creERT2 (Lgr5 ${ }^{\text {creERT2/+ }}$ ); Rosa26R; Apc ${ }^{\text {Min/+ }}$ mice, numerous blue stripes and blue polyps developed, comprising LacZ-labeled Lgr5-positive cell lineages (Fig. 2e-g). We traced LacZ expression in the polyps of Dclk1 $1^{\text {creERT2/+} ; ~ R o s a 26 R ; ~} A p c^{\mathrm{Min} /+}$ mice over time. One day after tamoxifen injection, 3.1\% of tumor cells were LacZ labeled (Fig. 2h). Then, labeled cells at the polyp base expanded daily to the luminal side, and finally occupied the whole polyp within 5-7 days (Fig. 2i-I). This rapid renewal of the tumor epithelium was

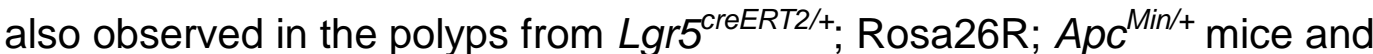
BrdU-pulsed $\mathrm{Apc}^{\mathrm{Min} /+}$ mice (Supplementary Fig. 8). Significantly, the number of blue polyps did not decrease by day 105 (Fig. $2 \mathrm{~m}, \mathrm{n}$ ). Apc ${ }^{\mathrm{Min} /+} ;$ Dclk1 $1^{\text {creERT2/creERT2 }}$ mice showed the same number and size of polyps as $A p c^{\mathrm{Min} /+}$ mice, suggesting that insertion of the creERT2 cassette did not affect the potential role of Dclk1 during tumorigenesis (Supplementary Fig. 9). Collectively, these data clearly indicated that Dclk1 marked TSCs capable of self-renewal and producing tumor progeny over a prolonged period.

Next, we elucidated the character of Dclk1 $1^{+}$cells in the tumors. In contrast to the normal intestine, a small proportion of Dclk1 ${ }^{+}$tumor cells expressed proliferation markers, particularly at the polyp base (Fig. 3a-c; Supplementary Fig. 10). Lgr5 was also expressed at the polyp base, where a proportion of Dclk1 ${ }^{+}$tumor cells were positive for Lgr5 (Fig. 3d-g). Combined with the finding that Dclk1 ${ }^{+}$cell lineages appeared to be generated from Dclk1 ${ }^{+}$cells at the polyp base (Fig. 2h-l), we hypothesized that the Dclk1- and Lgr5-double positive cells located at the polyp base were candidate TSCs in Apc ${ }^{\mathrm{Min} /+}$ mice. Importantly, few Dclk1 $^{+}$cells exhibited apoptosis (Fig. 3h, i). This suggests that Dclk1 might confer an antiapoptotic property to TSCs, in accordance with a previous report ${ }^{25}$. We then investigated the hierarchy between Dclk1 and Lgr5. Lgr5 ${ }^{\text {creERT2/+; }}$ Catnb1 $1^{\text {lox(ex3)/+ }}$ mice, in which cre recombination stabilizes $\beta$-catenin ${ }^{26}$, developed numerous intestinal polyps 40 days after tamoxifen injection (Supplementary Fig. 11a-d), as expected ${ }^{27}$. We found that Dclk1 ${ }^{+}$tumor cells colocalized with Lgr5 at the base of these polyps (Supplementary Fig. 12). In contrast, Dclk1 $1^{\text {creERT2/+}} ;$ Catnb1 $1^{\text {lox(ex3)/+ }}$ mice did not develop intestinal polyps, 
even 45 days after injection (Supplementary Fig. 11e-g). These data suggest that Dclk1 ${ }^{+}$cells in the normal intestine did not transform into TSCs directly and that Dclk1 expression arose secondarily in $\mathrm{Lgr}^{+} \mathrm{TSCs}$.

To ensure that Dclk1 ${ }^{+} / \mathrm{Lgr}^{+}$cells are bona fide TSCs, we compared the Dclk1 ${ }^{-} /$Lgr5 $^{-}$, Dclk1 ${ }^{+} /$Lgr5 $^{-}$, Dclk1 ${ }^{-} /$Lgr5 $^{+}$, and Dclk1 ${ }^{+} /$Lgr5 $^{+}$tumor cell populations by FACS analyses. Flow cytometry showed that anti-Dclk1 staining agreed with Dclk1-GFP, and the knock-in cassette was restricted to Dclk1 ${ }^{+}$cells in the polyps of Dclk1 ${ }^{\text {creERT2-IRES-EGFP/+}} ; A p c^{\text {Min/+ }}$ mice (Supplementary Fig. 13a, b). We sorted tumor cells based on the expression of Dclk1 and Lgr5-GFP in polyps from Lgr5 ${ }^{\text {EGFP-IRES-creERT2/++} ; \text { Catnb1 }}{ }^{\text {lox(ex3)/+ }}$ mice and the proportion of Dclk1 ${ }^{+} /$Lgr5 ${ }^{+}$tumor cells in the total Dclk1 ${ }^{+}$cells was $5.3 \%$ (Fig. 4a), in accordance with our immunohistochemical data. Flow cytometry demonstrated that the representative TSC marker CD44 and CD133 expression were highest in Dclk1 $1^{+} /$Lgr $^{+}$cells among the four cell populations (Fig. 4b, c). Dclk1 ${ }^{+} /$Lgr5 $^{+}$ tumor cells also showed the highest expression of $\mathrm{Bcl}-2$, a representative anti-apoptotic protein (Fig. 4d). Subsequently, we collected Lgr5 ${ }^{+}$tumor cells (Supplementary Fig. 13c), which were double-stained with antibodies against Dclk1 and proliferative or apoptotic markers. We occasionally observed Ki67 ${ }^{+}$ proliferative cells in $\mathrm{Dclk1}^{+} / \mathrm{Lgr} 5^{+}$cells, whereas we rarely detected $\mathrm{TUNEL}^{+}$ apoptotic cells (Fig. 4e-h). Expression of Cox-1, a Tuft cell marker, was higher in $\mathrm{Dclk}^{+} /$Lgr5 ${ }^{+}$and Dclk1 ${ }^{+} / \mathrm{Lgr}^{-}$tumor cells (Supplementary Fig. 13d). Overall, these results suggest that Dclk1 ${ }^{+} / \operatorname{Lgr} 5^{+}$cells have the potential of TSCs, with an antiapoptotic character ${ }^{28,29}$.

Finally, we investigated whether targeting TSCs marked by Dclk1 could be an effective antitumor therapy. In Dclk1 ${ }^{\text {creERT2/+} ; ~ R o s a 26 R ; ~} A p c^{\text {Min/+}}$; Rosa26 ${ }^{\text {iDTR/+ }}$ mice, cre activation induces the diphtheria toxin (DT) receptor in Dclk1 ${ }^{+}$cells, and administration of DT results in the death of these cells ${ }^{30,31}$ (Fig. 5a). After tamoxifen/DT treatment, LacZ-labeled cells disappeared from the normal intestine, without significant damage to organ architecture (Fig. 5b-e). Even after DT was administered 3 times daily for 3 days until $24 \mathrm{~h}$ after tamoxifen injection, we found no significant damage to normal tissues (Supplementary Fig. 14). In contrast, we observed severely injured or collapsed polyps over time after 
a single DT treatment (Fig. $5 f-j)$. To confirm that DT specifically induced the apoptosis of Dclk1 ${ }^{+}$cells, we examined the apoptotic status of Dclk1 ${ }^{+}$and Dclk1 ${ }^{-}$ tumor cells after DT treatment. We observed apoptotic Dclk ${ }^{+}$tumor cells at $12 \mathrm{~h}$ after DT injection, though apoptotic status of Dclk1 ${ }^{-}$tumor cells was not affected (Fig. 5k, Supplementary Figure 15a, b). At later time points, Dclk1 ${ }^{+}$tumor cells disappeared, and the proportion of total apoptotic cells returned to the basal level (Supplementary Figure 15). These data suggest that DT successfully eliminated Dclk1 ${ }^{+}$cells only without affecting other tumor cells. Combined with the finding that the turnover rate of polyps was approximately 7 days, it is suggested that the interruption of the tumor progeny supply by Dclk1 ${ }^{+} \mathrm{TSCS}$ resulted in tumor regression during this period.

In this study, we showed that Dclk1 did not mark NSCs but marked TSCs that were capable of continuously producing tumor progeny in the intestine of $A p c^{\mathrm{Min} /+}$ mice (Fig. 6a, b). Our lineage tracing analyses showed that the intestinal polyps of $A p c^{\mathrm{Min} /+}$ mice had a rapid turnover rate organized by TSCs. We suggest that $\mathrm{Dclk} 1^{+} / \mathrm{Lgr} 5^{+}$cells at the tumor base have a character of TSCs in a hierarchical system in murine intestinal adenoma, which agrees with a previous report that stem cell-like tumor cells exist at the base of human $\mathrm{CRCs}^{32}$. Other stem cell markers may substitute for Lgr5 as a partner of Dclk1 because $\mathrm{Dclk}^{+} / \mathrm{Lgr} 5^{+}$cells had higher expression of CD44 and CD133. Even so, it is particularly notable that the specific ablation of $\mathrm{Dclk} 1^{+} \mathrm{TSC}$ resulted in tumor regression without significant damage to normal tissues (Fig. 6c). Though we implemented restrictive ablation method to kill the TSCs specifically, there remained the possibility that DT treatment affect the immediate progeny, not only the TSCs because of technical limitation. However, our analysis for apoptosis of Dclk1 ${ }^{+}$and other tumor cells suggested that DT specifically targeted Dclk1 ${ }^{+}$cells and caused tumor regression. Thus, Dclk1 appeared to be a unique marker for distinguishing TSCs from intestinal NSCs. The similar Dclk1 expression pattern in humans and mice (Supplementary Fig. 1) led us to propose the possibility of targeting Dclk $1^{+}$tumor cells for the treatment of human CRCs. This study provides insights into the therapeutic potential of targeting cancer stem cells. 


\section{ACKNOWLEDGEMENT}

We thank Professor K. Kohno (Nara Institute of Science and Technology) for kindly providing diphtheria toxin. We also thank Y. Kimura, S. Ishizu, M. Nakatsuji, R. Akitake-Kawano, K. Furuyama, and T.S. Stappenbeck for technical assistances and helpful suggestions. This work was supported by JSPS KAKENHI 10J02434, 21229009, 23590937, 24229005, 24659363, 24590914, and 24590916; Research program of the Project for Development of Innovative Research on Cancer Therapeutics (P-Direct) from Ministry of Education, Culture, Sports, Science and Technology of Japan; Health and Labour Sciences Research Grants for Research on Intractable Diseases, Hepatitis, and The innovative development and the practical application of new drugs for hepatitis $B$ from the Ministry of Health, Labour and Welfare, Japan; the Funding Program for Next-Generation World-leading Researchers (LS075), Grants-in Aid from the Ministry of Education, Culture, Science, Sports and Technology of Japan; Princess Takamatsu Cancer Research Fund 10-24212, Japan.

\section{AUTHOR CONTRIBUTION}

Y.N. and H.S. designed the study. Y.N., H.S., A.F., T.U., T.M., N.N., and K.Kanda performed the experiments. Y.N., H.S., and A.I. analyzed the data. Y.N., H.S., Y.K., and T.C. prepared the manuscript with input from the other authors. K.Kawada, Y.S., M.Y., and M.M.T. provided essential materials. Y.Y., H.K., M.K., gave technical support and discussion. M.Y., R.K., Y.K., M.M.T., S.Y., and T.C. supervised the project.

\section{COMPETING FINANCIAL INTERSET}

The authors declare no competing financial interests.

\section{FIGURE LEGENDS}

Fig. 1. Dclk1 marked postmitotic cells rather than NSCs in the intestine.

a, Experimental strategy of tamoxifen-inducible cre-mediated cell tracking using Dclk1 ${ }^{\text {creERT2/+} ; ~ R o s a 26 R ~ m i c e . ~ b, ~ R e p r e s e n t a t i v e ~ m a c r o s c o p i c ~ i m a g e s ~ o f ~}$ 
LacZ-labeled blue Dclk1 ${ }^{+}$cells (black dotted circles) on days 1 (left) and 7 (right) after a single tamoxifen injection. c, Representative LacZ staining (black dotted circles) in the small intestine on days 1, 7, and 14. d, The number and localization of blue-labeled Dclk1 ${ }^{+}$cells per 1000 crypt-villus units after injection $(n=3)$. Crypt-villus junction (CVJ) indicated the boundary between the higher crypt and the villus, which was designated from histology. e, The number of blue-labeled Dclk $1^{+}$cells decreased on a daily basis in the intestine $(n=3) . \mathrm{f}$, Immunofluorescent staining showed Dclk1 ${ }^{+}$cells (green) negative for BrdU (red) (yellow dotted box). g, BrdU-positive cells were not detected in 1000 Dclk ${ }^{+}$cells in the normal intestine. N.D., not detected. Bars, $50 \mu \mathrm{m}$ (b, c) and $10 \mu \mathrm{m}$ (f).

\section{Fig. 2. Dclk1 marked TSCs in the polyps of $A p c^{M i n /+}$ mice.}

a, Strategy for tamoxifen-inducible cre-mediated cell tracking using $D c / k 1^{\text {creERT2/+ }}$ or Lgr5-EGFP-IRES-creERT2 (Lgr5 ${ }^{\text {creERT2/+ }) \text {; Rosa26R; Apc }}{ }^{\text {Min/+ }}$ mice. b-d, Macroscopic images of the small intestine and polyps (red dotted circles) in Dclk1 $1^{\text {creERT2/+} ; ~ R o s a 26 R ; ~} A p c^{\text {Min/+ }}$ mice 7 days after tamoxifen injection; the polyps turned "blue" (b). Representative magnified image (c) and coronal section (d) of "blue polyps." Only scattered LacZ expression was detected in the villi (d, *). e-g, Macroscopic images of the small intestine and polyps (red dotted circles) in Lgr5 ${ }^{\text {creERT2/+; }}$ Rosa26R; $A p c^{\mathrm{Min/+}}$ mice 7 days after injection; most polyps and villi turned blue (e). Representative magnified image (f) and coronal section (g) of blue polyps. It was noteworthy that the villi turned blue (g, *). h-k, LacZ staining on days 1 (h), 3 (i), 5 (j), and 7 (k) after a single tamoxifen injection in the polyps of Dclk1 ${ }^{\text {creERT2/+} ; ~ R o s a 26 R ; ~} A p c^{\text {Min/+ }}$ mice. I, Dclk1 expression (red dotted circles) was observed in cells at the base of LacZ-stained polyps. $\mathrm{m}$, Representative histology (left), macroscopic image (upper right, red dotted circles) and magnified view of macroscopic image (lower right) of blue polyps on day 105 after injection. $n$, The number of blue polyps had not decreased by day 105. Bars, $2 \mathrm{~mm}$ (b, e, m upper right) and $50 \mu \mathrm{m}$ (c, d, f-l, m left and lower right).

Fig. 3. Dclk1 ${ }^{+} / \mathrm{Lgr}^{+}$tumor cells were observed at the base of intestinal polyps. 
a, Colocalization of BrdU (red) and Dclk1 (green) at the polyp base (yellow dotted box) in Dclk1 $1^{\text {creERT2/+}} ; A p c^{\mathrm{Min} /+}$ mice. b, BrdU-positive cells per $1000 \mathrm{Dclk1}^{+}$ cells in polyps and normal mucosa were counted. A proportion of Dclk1 $1^{+}$cells was positive for BrdU in the polyps (-p), contrary to the normal mucosa (Min-m). c, The proportion of BrdU-positive Dclk1 ${ }^{+}$tumor cells was significantly higher at the polyp base. $d$, Immunofluorescent analysis of Lgr5 (GFP) expression in Lgr5 ${ }^{\text {creERT2/+}} ; A p c^{\mathrm{Min/+}}$ mice. The yellow dotted box indicates that Lgr5 (GFP, green) ${ }^{+}$tumor cells positive for nuclear $\beta$-catenin (red) were located mainly at the polyp base. e, Colocalization of Dclk1 (red) and Lgr5 (GFP, green) at the polyp base (yellow dotted box). f, Lgr5 (GFP)-stained cells per 1000 Dclk1 $^{+}$cells in polyps and normal mucosa were counted. The proportion of Dclk1 $1^{+} / \mathrm{Lgr} 5^{+}$cells was significantly higher in polyps (-p) than in the normal mucosa (Min-m). $g$, The proportion and localization of Dclk1 ${ }^{-} / \mathrm{Lgr}^{-}, \mathrm{Dclk}^{+} / \mathrm{Lgr}^{-}, \mathrm{Dclk}^{-} / \mathrm{Lgr}^{+}$, and Dclk1 ${ }^{+} / \operatorname{Lgr} 5^{+}$tumor cells are shown. It is noteworthy that Dclk1 $1^{+} / \mathrm{Lgr} 5^{+}$cells were observed mainly at the polyp base. $\mathrm{h}$, Immunofluorescent analysis showed that Dclk $1^{+}$cells (GFP, green) rarely colocalized with cleaved caspase 3 (red) (yellow dotted box). i, Cleaved caspase 3-stained cells per 1000 Dclk1 $^{+}$cells or Dclk1cells in the polyps were counted. The proportion of both cohorts is shown, suggesting that Dclk1 ${ }^{+}$cells were non-apoptotic. N.D., not detected. ${ }^{\star} P<0.05$. Bars, $50 \mu \mathrm{m}$.

\section{Fig. 4. Dclk1 ${ }^{+} / \mathrm{Lgr} 5^{+}$cells had a character of TSCs in intestinal polyps.}

a, Tumor cells were sorted on the basis of Dclk1 and Lgr5 (GFP) expression in Lgr5 $^{\text {creERT2/+}}$; Catnb ${ }^{\text {lox(ex3)/+ }}$ mice 40 days after tamoxifen injection. The proportion of Dclk1 ${ }^{+} / \mathrm{Lgr}^{+}$tumor cells in total Dclk1 ${ }^{+}$cells was $5.3 \%$. The proportion of $\mathrm{Dclk}^{+} / \mathrm{Lgr} 5^{+}$tumor cells of the total $\mathrm{Lgr}^{+}$cells was $2.6 \%$. FSC, forward scatter; SSC, side scatter. b-d, Flow cytometry showed the expression levels of CD44 (b), CD133 (c), and Bcl2 (d) in each population of Dclk1 ${ }^{-} / \mathrm{Lgr5}^{-}, \mathrm{Dclk}^{+} / \mathrm{Lgr5}^{-}$, $\mathrm{Dclk1}^{-} / \mathrm{Lgr}^{+}$, and Dclk1 ${ }^{+} / \mathrm{Lgr}^{+}$tumor cells. A higher expression of CD44, CD133, and $\mathrm{Bcl} 2$ was observed in the Dclk1 $1^{+} / \mathrm{Lgr} 5^{+}$fraction compared with the other three. e, Sorted Lgr5 ${ }^{+}$tumor cells were double-stained with antibodies against Dclk1 (green) and Ki67 (red). Dclk1 $1^{+} / \operatorname{Lgr}^{+}$cells occasionally colocalized with 
Ki67. f, Sorted Lgr5 ${ }^{+}$tumor cells were examined by anti-Dclk1 immunostaining (green) and TUNEL (red). Dclk1 $1^{+} / \mathrm{Lgr}^{+}$cells were rarely positive for TUNEL. g, Approximately $1 \times 10^{3}$ sorted $\mathrm{Lgr}^{+}$or $\mathrm{Lgr}^{-}$cells were double stained against Dclk1 and Ki67. The proportion of Ki67-positive proliferating cells in each population of Dclk1 ${ }^{-} / \mathrm{Lgr}^{-}$, Dclk1 ${ }^{-} / \mathrm{Lgr}^{+}$, Dclk1 ${ }^{+} / \mathrm{Lgr}^{-}$, and Dclk1 ${ }^{+} / \mathrm{Lgr}^{+}$tumor cells is shown. N.D., not detected. h, Approximately $1 \times 10^{3}$ sorted Lgr5 ${ }^{+}$or Lgr5 ${ }^{-}$ cells were examined by anti-Dclk1 immunostaining and TUNEL. The proportion of TUNEL-positive apoptotic cells in each population of Dclk1 ${ }^{-} / \mathrm{Lgr}^{-}$, Dclk1 ${ }^{-} / \mathrm{Lgr}^{+}, \mathrm{Dclk}^{+} / \mathrm{Lgr5}^{-}$, and Dclk $1^{+} / \mathrm{Lgr} 5^{+}$tumor cells is shown. Dclk1 ${ }^{+}$cell fractions were significantly less apoptotic than Dclk1 ${ }^{-}$cell fractions. N.D., not detected. ${ }^{\star} P<0.05$. Bars, $10 \mu \mathrm{m}$.

Fig. 5. Ablation of TSCs marked by Dclk1 resulted in tumor regression without significant damage to normal intestine.

a, Strategy of tamoxifen and diphtheria toxin (DT)-mediated ablation of Dclk1 ${ }^{+}$

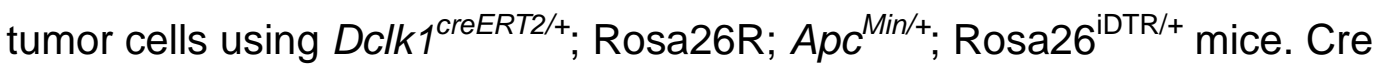
activation induces DT receptors in Dclk1 ${ }^{+}$cells, and administration of DT induces selective death of these cells. b, Schedule of specific ablation of Dclk1 ${ }^{+}$TSCs. To kill the Dclk1 ${ }^{+}$cells exclusively, a single DT was injected $24 \mathrm{~h}$ after tamoxifen induction. Mice were analyzed on days 1, 3, and 5 after DT injection. c, Without DT treatment, blue-labeled Dclk1 ${ }^{+}$cells (black dotted circles) were detected on day 5. d, Following DT treatment, blue-labeled cells were rarely detected. e, Numbers of blue-labeled cells with (DT(+)) or without (DT(-)) DT treatment on day $5(n=6)$. f, Without DT treatment, scattered blue Dclk1 ${ }^{+}$tumor cells were observed including cells near the polyp base (black dotted box) $24 \mathrm{~h}$ after tamoxifen injection. $\mathrm{g}-\mathrm{i}$, Representative $\mathrm{H} \& \mathrm{E}$ staining of the injured or collapsed polyps on days 1 (g), 3 (h, black arrows), and 5 (I, black dotted circle) after DT injection. j, The number of the intact polyps was significantly decreased in DT-treated mice $(n=6) . \mathrm{k}$, Immunofluorescent staining indicated the colocalization of cleaved caspase 3 (red) and Dclk1 (GFP, green) $12 \mathrm{~h}$ after DT injection (yellow dotted box), suggesting that DT specifically killed Dclk1 ${ }^{+}$cells 
including cells at the polyp base. ${ }^{\star} P<0.05$. Bars, $50 \mu \mathrm{m}$.

Fig. 6. Dclk1 is a marker for TSCs rather than NSCs in the intestine.

$a, b$, Model for the role of Dclk1 in the normal intestine (a) and tumors (b). (a) Most Dclk1 ${ }^{+}$cells (green) are postmitotic and shed within a few weeks (top), whereas Lgr5 ${ }^{+}$NSCs (dark blue) continuously produce their progeny (pale blue) in the intestine (bottom). (b) Dclk1 is expressed in Lgr5 ${ }^{+}$TSCs (dark purple) that continuously produce tumor progeny (light purple). $d$, Model for the antitumor therapy targeting Dclk $1^{+}$cells. (1) Targeting Dclk1 ${ }^{+}$cells (green) does not cause mucosal damage to the normal intestine. (2) Elimination of TSCs marked by Dclk1 (dark purple) leads to the tumor collapse.

\section{REFERENCE}

1. Dalerba, P. et al. Phenotypic characterization of human colorectal cancer stem cells. Proc Natl Acad Sci U S A 104, 10158-63 (2007).

2. O'Brien, C.A., Pollett, A., Gallinger, S. \& Dick, J.E. A human colon cancer cell capable of initiating tumour growth in immunodeficient mice. Nature 445, 106-10 (2007).

3. Zhu, L. et al. Prominin 1 marks intestinal stem cells that are susceptible to neoplastic transformation. Nature 457, 603-7 (2009).

4. Todaro, M., Francipane, M.G., Medema, J.P. \& Stassi, G. Colon cancer stem cells: promise of targeted therapy. Gastroenterology 138, 2151-62 (2010).

5. Giannakis, M. et al. Molecular properties of adult mouse gastric and intestinal epithelial progenitors in their niches. J Biol Chem 281, $11292-300$ (2006).

6. May, R. et al. Identification of a novel putative gastrointestinal stem cell and adenoma stem cell marker, doublecortin and CaM kinase-like-1, following radiation injury and in adenomatous polyposis coli/multiple intestinal neoplasia mice. Stem Cells 26, 630-7 (2008).

7. Gerbe, F., Brulin, B., Makrini, L., Legraverend, C. \& Jay, P. DCAMKL-1 expression identifies Tuft cells rather than stem cells in the adult mouse 
intestinal epithelium. Gastroenterology 137, 2179-80; author reply 2180-1 (2009).

8. Saqui-Salces, M. et al. Gastric tuft cells express DCLK1 and are expanded in hyperplasia. Histochem Cell Biol 136, 191-204 (2011).

9. Barker, N. et al. Identification of stem cells in small intestine and colon by marker gene Lgr5. Nature 449, 1003-7 (2007).

10. Sangiorgi, E. \& Capecchi, M.R. Bmi1 is expressed in vivo in intestinal stem cells. Nat Genet 40, 915-20 (2008).

11. Bonnet, D. \& Dick, J.E. Human acute myeloid leukemia is organized as a hierarchy that originates from a primitive hematopoietic cell. Nat Med 3, 730-7 (1997).

12. Al-Hajj, M., Wicha, M.S., Benito-Hernandez, A., Morrison, S.J. \& Clarke, M.F. Prospective identification of tumorigenic breast cancer cells. Proc Natl Acad Sci U S A 100, 3983-8 (2003).

13. Singh, S.K. et al. Identification of a cancer stem cell in human brain tumors. Cancer Res 63, 5821-8 (2003).

14. Li, C. et al. Identification of pancreatic cancer stem cells. Cancer Res 67, 1030-7 (2007).

15. Ricci-Vitiani, L. et al. Identification and expansion of human colon-cancer-initiating cells. Nature 445, 111-5 (2007).

16. Cocciadiferro, L. et al. Profiling cancer stem cells in androgen-responsive and refractory human prostate tumor cell lines. Ann N Y Acad Sci 1155, 257-62 (2009).

17. Clevers, $\mathrm{H}$. The cancer stem cell: premises, promises and challenges. Nat Med 17, 313-9 (2011).

18. Davies, E.J., Marsh, V. \& Clarke, A.R. Origin and maintenance of the intestinal cancer stem cell. Mol Carcinog 50, 254-63 (2011).

19. May, R. et al. Doublecortin and CaM kinase-like-1 and leucine-rich-repeat-containing G-protein-coupled receptor mark quiescent and cycling intestinal stem cells, respectively. Stem Cells 27, 2571-9 (2009). 
20. Gerbe, F. et al. Distinct ATOH1 and Neurog3 requirements define tuft cells as a new secretory cell type in the intestinal epithelium. J Cell Biol 192, 767-80 (2011).

21. Koizumi, H., Tanaka, T. \& Gleeson, J.G. Doublecortin-like kinase functions with doublecortin to mediate fiber tract decussation and neuronal migration. Neuron 49, 55-66 (2006).

22. Sauer, B. \& Henderson, N. Targeted insertion of exogenous DNA into the eukaryotic genome by the Cre recombinase. New Biol 2, $441-9$ (1990).

23. Soriano, P. Generalized lacZ expression with the ROSA26 Cre reporter strain. Nat Genet 21, 70-1 (1999).

24. Vermeulen, L. et al. Single-cell cloning of colon cancer stem cells reveals a multi-lineage differentiation capacity. Proc Natl Acad Sci U S A 105, 13427-32 (2008).

25. Verissimo, C.S. et al. Silencing of the microtubule-associated proteins doublecortin-like and doublecortin-like kinase-long induces apoptosis in neuroblastoma cells. Endocr Relat Cancer 17, 399-414 (2010).

26. Harada, N. et al. Intestinal polyposis in mice with a dominant stable mutation of the beta-catenin gene. EMBO J 18, 5931-42 (1999).

27. Barker, N. et al. Crypt stem cells as the cells-of-origin of intestinal cancer. Nature 457, 608-11 (2009).

28. Visvader, J.E. \& Lindeman, G.J. Cancer stem cells in solid tumours: accumulating evidence and unresolved questions. Nat Rev Cancer 8 , 755-68 (2008).

29. Graham, S.M. et al. Primitive, quiescent, Philadelphia-positive stem cells from patients with chronic myeloid leukemia are insensitive to STI571 in vitro. Blood 99, 319-25 (2002).

30. Saito, M. et al. Diphtheria toxin receptor-mediated conditional and targeted cell ablation in transgenic mice. Nat Biotechnol 19, 746-50 (2001).

31. Buch, T. et al. A Cre-inducible diphtheria toxin receptor mediates cell lineage ablation after toxin administration. Nat Methods 2, 419-26 (2005). 
32. Merlos-Suárez, A. et al. The intestinal stem cell signature identifies colorectal cancer stem cells and predicts disease relapse. Cell Stem Cell 8, 511-24 (2011). 


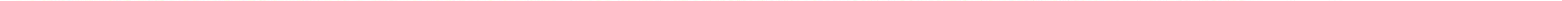


(3) 京都大学itestine

A Self-archived copy in Kyoto University Research Information Rep

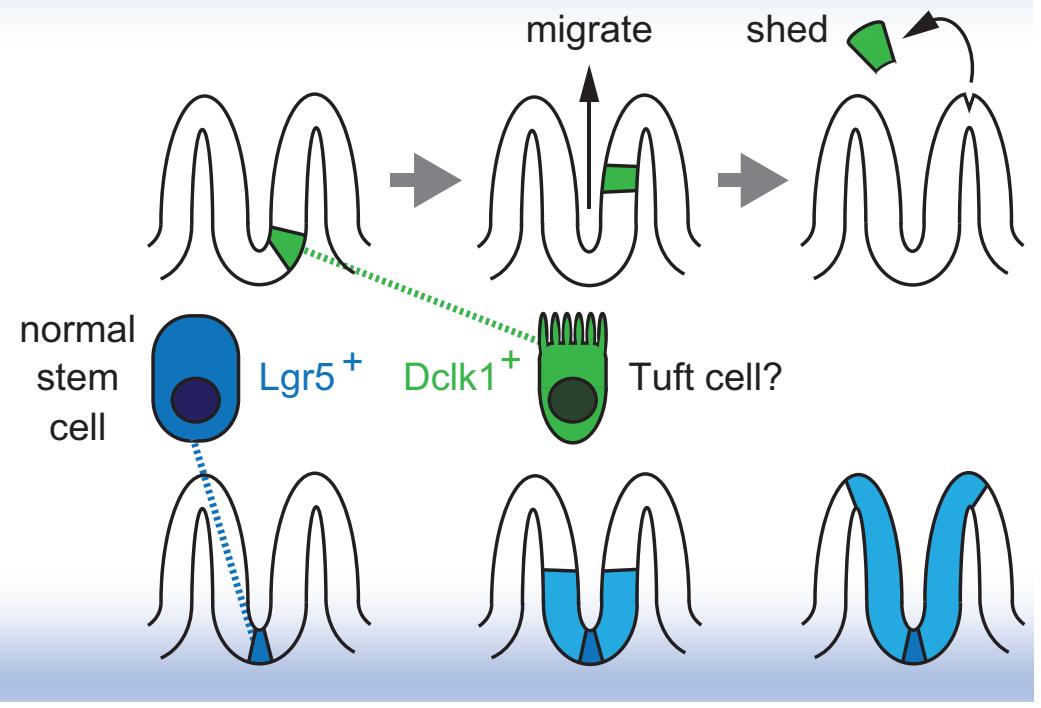

b Tumor

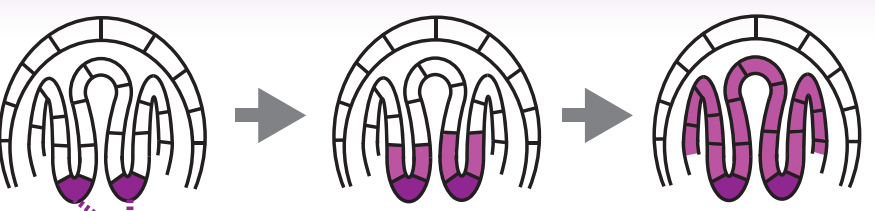

tumor

stem

cell
$\operatorname{Lgr}^{+}$

Dclk1 ${ }^{+}$
C Targeting of Dclk1-exKURENAl 红

(1) Normal intestine

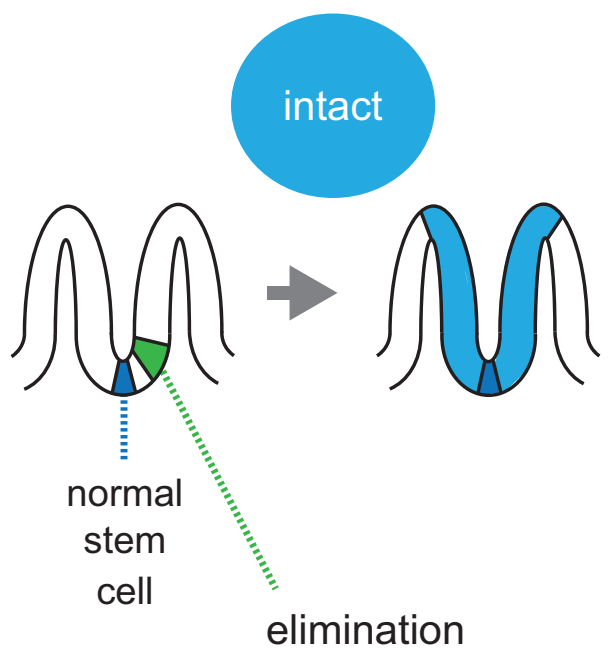

(2) Tumor

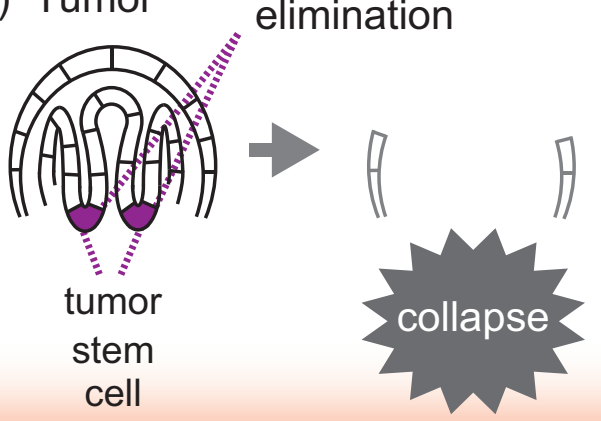




\section{ONLINE METHODS}

Mice. Dclk1-creERT2-IRES-EGFP mice were generated by high-fidelity polymerase chain reaction (PCR) from genomic BAC clone RP23-132B14, 2.5-kilobase $(\mathrm{kb})$ upstream of the ATG start codon of the mouse Dclk1 gene and $6.1 \mathrm{~kb}$ downstream of the end of exon 2. After all components were sequence verified, these Dclk1 flanking arms were cloned into pBluescriptll $\mathrm{SK}^{+}$plasmid containing the creERT2-IRES-EGFP cassette, as depicted in Supplementary Figure 2. The expression construct $(25 \mu \mathrm{g})$ was linearized and transfected into C57/BL6 mouse embryonic stem (ES) cells by electroporation.

Neomycin-resistant recombinant ES clones were selected in the medium containing G418 for 7 days. A total of 231 recombinant ES clones were transferred into 96-well plates and cultured to 70\% confluence. Plates were then duplicated, one cryopreserved, and one continued in culture to $100 \%$ confluence for DNA isolation. DNA from all clones was screened for correct targeting by long PCR with primers flanking the 5' short arm. All positive clones and randomly selected negative clones were then confirmed by Southern blotting using the $5^{\prime}$ and 3' probes indicated in Supplementary Figure 2. Six positive clones were thawed, expanded and injected into Balb/c blastocysts using standard procedures. Male chimeras born after transplantation of the blastocysts into ICR foster mothers were subsequently mated with C57BL/6 females, and germline transmission was confirmed by screening offspring for the presence of the expression cassette in the Dclk1 locus by PCR. The neomycin selection cassette was later excised in vivo by crossing with FLP mice. Rosa26R mice, Rosa26-iDTR mice, Lgr5-EGFP-IRES-creERT2 mice, and $A p c^{\mathrm{Min} /+}$ mice were obtained from the Jackson Laboratory. Generation of Catnb1 $1^{\operatorname{lox}(e x 3)}$ mice was carried out as described previously ${ }^{26}$. All experiments were approved by the animal research committee of Kyoto University and performed in accordance with Japanese government regulations.

Tamoxifen injection. For lineage tracing experiments in normal tissues and polyps, >8-week-old Dclk1 $1^{\text {creERT2/+ }}$; Rosa26R mice or 14-week-old Dclk1 ${ }^{\text {creERT2/+; }}$ Rosa26R; $A p c^{\mathrm{Min} /+}$ mice were injected intraperitoneally with $200 \mu \mathrm{l}$ of tamoxifen 
(Sigma) in corn oil at $20 \mathrm{mg} \mathrm{ml}^{-1}$. For tumor formation experiments, >8-week-old Lgr5 $^{\text {creERT2/+ }}$ or Dclk1 $1^{\text {creERT2/+ }}$; Catnb $b^{\text {lox(ex3)/+ }}$ mice were injected with the same dose of tamoxifen. For ablation experiments of Dclk1 ${ }^{+}$tumor cell ablation experiments, 14-week-old Dclk1 ${ }^{\text {creERT2/+} ; ~ R o s a 26 R ; ~} A p c^{\mathrm{Min} /+}$; Rosa26 ${ }^{\text {iDTR/+ }}$ mice were injected with the same dose of tamoxifen.

Diphtheria toxin (DT) injection. DT was generously provided by Professor K. Kohno. Fourteen-week-old Dclk1 ${ }^{\text {creERT2/+} ; ~ R o s a 26 R ; ~} A p c^{\text {Min/+* }}$; Rosa26 ${ }^{\text {iDTR/+ }}$ mice were injected intraperitoneally with $100 \mathrm{ng}$ DT in PBS. In the single DT injection protocol, DT was given $24 \mathrm{~h}$ after tamoxifen administration. In the multiple DT injection protocol, DT was given 3 times daily with $8 \mathrm{~h}$ interval for 3 days, and the final injection was applied $24 \mathrm{~h}$ after tamoxifen administration. It has been reported that the serum concentration of DT which we used in our experiments decreased to $<15 \%$ of the maximum concentration at $24 \mathrm{~h}$ after the injection ${ }^{30}$. To support the notion that Dclk1 ${ }^{+}$cells were specifically killed by DT and that their progeny was unaffected by DT, which might persist until later time points, we injected $15 \mathrm{ng}$ of DT (15\% of the dose we used in the ablation experiment) to Dclk1 ${ }^{\text {creERT2/+ }}$; Rosa26R; Apc $c^{\mathrm{Min} /+} ;$ Rosa26 $6^{\mathrm{iDTR} /+}$ mice. Then, the number of blue cells in the normal intestine and blue polyps was not decreased after DT injection (Supplementary Figure 16), indicating that Dclk1 ${ }^{+}$cells were not killed by this low-dose DT protocol. This finding suggested that a single injection of $100 \mathrm{ng}$ DT did not have a significant effect after the next day of DT injection in our ablation model.

Injury models. Injury experiments were performed using $>8$-week-old mice. For irradiation-induced injury model, mice were treated with $8 \mathrm{~Gy}$ irradiation. For dextran sodium sulfate (DSS)-induced colitis model, mice were treated with 2.0\% DSS (MP Biomedicals) given in drinking water for 7 consecutive days. In both models, a single tamoxifen injection ( $4 \mathrm{mg}$ ) was given just before the end of injury. 
Histological analysis. For histological analysis, mouse organs were isolated and fixed overnight in 4\% paraformaldehyde (PFA), embedded in paraffin, and sectioned at a thickness of 3-5 $\mu \mathrm{m}$. Sections were then deparaffinized, rehydrated, and stained with hematoxylin and eosin ( $\mathrm{H} \& \mathrm{E})$. For immunohistochemistry, sections were incubated with primary antibody overnight and with the biotinylated secondary antibody, followed by incubation with avidin biotin-peroxidase complex (Vector Labs), labeled with peroxidase, and colored with diaminobenzidine substrate (Dako). For immunofluorescence, sections were incubated with the primary antibodies overnight at $4^{\circ} \mathrm{C}$ and washed again with PBS. Washed sections were treated with fluorescence-conjugated secondary antibodies (Invitrogen) for $1 \mathrm{~h}$. For immunofluorescent analysis on Lgr5 expression, we had immunostained Lgr5-positive cells with anti-GFP antibodies using Lgr5 ${ }^{\text {EGFP-IRES-CreERT2 }}$ mice. Immunohistochemical analysis of human samples was carried out by the same procedure as described above. For immunocytochemistory, sorted tumor cells were attached to the slide glasses using CytoSpin (Thermo Scientific). Sections were fixed with acetone/methanol (3:7), permeabilized with PBS containing 0.1\% Tween20 (Sigma), incubated with the primary antibodies overnight at $4^{\circ} \mathrm{C}$, and treated with fluorescence-conjugated secondary antibodies (Invitrogen) for $1 \mathrm{~h}$. Primary antibodies included rabbit anti-mouse Dclk1 (1:200; Abcam), mouse anti-human Epcam (1:100; Cell Signaling Technology (CST)), mouse anti-human Ki67 (1:100; Dako), rat anti-mouse Ki67 (1:100; Dako), mouse anti-PCNA (1:100; BD Biosciences), rabbit anti-mouse Muc2 (1:50; Santa Cruz), rabbit anti-mouse chromogranin A (1:200; Santa Cruz), rabbit anti-human lysozyme (1:200; Dako), mouse anti-human $\beta$-catenin (1:100; BD Biosciences), rabbit anti-mouse cleaved caspase3 (1:100; CST), and chicken anti-mouse GFP (1:1000, Abcam). For proliferation assays using BrdU (Fig. 1g, h, and Fig. 3a-c), $300 \mu \mathrm{l}$ of BrdU (Roche) was injected $2 \mathrm{~h}$ before the mice were killed. For BrdU pulse and chase study (Supplementary Fig. 8), $300 \mu \mathrm{l}$ of BrdU was injected into 14-week-old $A p c^{\mathrm{Min} /+}$ mice 3 times at $3 \mathrm{~h}$ interval. Tissues or sorted tumor cells were stained using 5'-Bromo-2'-deoxyuridine Labeling \& Detection Kit as recommended by 
the manufacturer (Roche). TUNEL was performed using In Situ Cell Death Detection Kit, TMR red (Roche).

$\beta$-galactosidase (LacZ) staining protocol. Organs were isolated and immediately incubated for $2 \mathrm{~h}$ in a 20 -fold volume of ice-cold fixative solution (PBS containing 4\% PFA, 5 mM EGTA, $2 \mathrm{mM} \mathrm{MgCl}_{2}, 0.2 \%$ glutaraldehyde, and $0.02 \% \mathrm{NP} 40$ ) at $4^{\circ} \mathrm{C}$ on a rolling platform. Small intestine and colon were first cleaned by flushing with PBS to remove feces. The fixative was removed and the tissues washed twice in PBS for 20 min at room temperature $\left(20^{\circ} \mathrm{C}\right)$ on a rolling platform. $\beta$-galactosidase substrate (PBS containing $5 \mathrm{mM} \mathrm{K}_{3} \mathrm{~F}(\mathrm{CN})_{6}, 5$ $\mathrm{mM} \mathrm{K}_{4} \mathrm{Fe}(\mathrm{CN})_{6} \cdot 3 \mathrm{H}_{2} \mathrm{O}, 2 \mathrm{mM} \mathrm{MgCl} 2,0.02 \% \mathrm{NP} 40,0.1 \%$ sodium deoxycholate, and $1 \mathrm{mg} \mathrm{ml}^{-1} \mathrm{X}$-gal) was then added and the tissues incubated in the dark overnight at room temperature. The substrate was removed and the tissues washed twice in PBS for 20 min at room temperature. The tissues were then fixed overnight in a 20 -fold volume of $4 \%$ PFA in PBS at $4^{\circ} \mathrm{C}$ in the dark on a rolling platform. The PFA was removed and the stained tissues were transferred to tissue cassettes and paraffin blocks prepared using standard methods. Tissue sections $(5 \mu \mathrm{m})$ were prepared and counterstained with nuclear fast red (KPL).

Polyp dissociation, flow cytometry, and cell sorting. Mouse intestinal

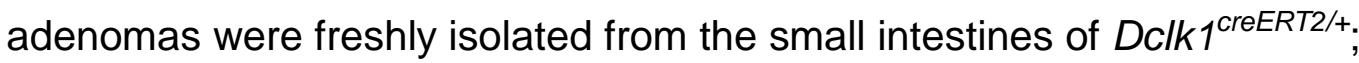
$A p c^{\mathrm{Min} /+}$ or Lgr5 ${ }^{\mathrm{creERT2/+}}$; Catnb $\mathrm{lox}^{\mathrm{lex} 3) /+}$ mice. The adenoma tissue was minced and incubated with digestion buffer (Dulbecco's modified Eagle medium with 10\% FCS, penicillin/streptomycin (Invitrogen), $1 \mathrm{mg} / \mathrm{mL}$ collagenase type 11 (Sigma), and DNase I ( 1 units $/ \mu \mathrm{l})$ for $20 \mathrm{~min}$ at $37^{\circ} \mathrm{C}$. After the incubation, cells were filtered through a 40- $\mu \mathrm{M}$ mesh, shaken vigorously, and incubated with PBS containing $2 \mathrm{mmol} / /$ EDTA for $20 \mathrm{~min}$ at $4^{\circ} \mathrm{C}$. The dissociated cells were fixed with formalin, permeabilized with perm/wash buffer (BD Biosciences), and incubated with antibodies against Dclk1, CD44, CD133, Bcl2, and Cox-1 on ice for 30 min. Cells stained with primary antibodies received secondary staining with fluorescence-conjugated antibodies. Labeled cells were run on a FACSAria 
II (BD biosciences), and analyzed using the FlowJo software (version 7.6.1, Tree Star). To obtain $\mathrm{Lgr}^{+}$tumor cells, GFP-expressing cells were sorted by FACSAria II. Dead cells were labeled with PI or 7-AAD and excluded from the analysis. The antibodies used for flow cytometry included rabbit anti-mouse Dclk1 (1:100; Abcam), rat anti-mouse CD44 (1:100; Abcam), rat anti-mouse CD133 (1:100; Abcam), mouse anti-human Bcl2 (1:100; Abcam), and goat anti-mouse Cox-1 (1:100; Santa Cruz).

RNA isolation and quantitative RT-PCR. RNA was extracted from the sorted tumor cells in small intestinal polyps of Dclk1 $1^{\text {creERT2/+}} ; A p c^{M i n /+}$ mice using RNeasy Micro Kit (Qiagen) according to the manufacturer's instructions; then, single-stranded cDNA was synthesized using Superscript III (Invitrogen). Quantitative PCR was performed using the Light Cycler FastStart DNA Master SYBR Green 1 kit (Roche Diagnostics). The amplification conditions included 10 seconds of denaturation at $95^{\circ} \mathrm{C}, 5$ seconds of annealing at $57^{\circ} \mathrm{C}$, and 10 seconds of extension at $72^{\circ} \mathrm{C}$ for a total of 45 cycles.

Human subjects. Analyses for human subjects were approved by the ethical committee of Kyoto University Hospital, and written informed consent was obtained from all the subjects. Tissue samples were obtained from 80 patients with colorectal cancer during surgery at Kyoto University Hospital; any information identifying subjects has been omitted. Samples were processed for immunohistological studies after fixing in 10\% formalin. The percentage of Dclk $1^{+}$cancer cells was determined by three authors (Y.N., H.S., and K.Kanda) based on the staining of 10 randomly selected high power fields $(\times 400)$ for each sample.

Statistics. All values are presented as mean \pm S.D. unless otherwise stated. The two-tailed Student's $t$-test or chi-square test, and Fisher's exact test were used for statistical analysis. $P$-values of $<0.05$ were considered significant. 
Dclk1 distinguishes between tumor and normal stem cells in the intestine

Yuki Nakanishi ${ }^{1}$, Hiroshi Seno ${ }^{1}$, Ayumi Fukuoka ${ }^{2}$, Taro Ueo ${ }^{1}$, Yuichi Yamaga ${ }^{1}$, Takahisa Maruno ${ }^{1}$, Naoko Nakanishi ${ }^{1}$, Keitaro Kanda ${ }^{1}$, Hideyuki Komekado', Mayumi Kawada ${ }^{1}$, Akihiro Isomura ${ }^{3}$, Kenji Kawada ${ }^{4}$, Yoshiharu Sakai ${ }^{4}$, Motoko Yanagita ${ }^{5}$, Ryoichiro Kageyama ${ }^{3}$, Yoshiya Kawaguchi ${ }^{6}$, Makoto M. Taketo $^{7}$, Shin Yonehara ${ }^{2}$, Tsutomu Chiba ${ }^{1}$

${ }^{1}$ Department of Gastroenterology and Hepatology, Kyoto University Graduate School of Medicine, Kyoto, Japan. '2Laboratory of Molecular and Cellular Biology, Graduate School of Biostudies, Kyoto University, Kyoto, Japan. ${ }^{3}$ Institute for Virus Research, Kyoto University, Kyoto, Japan. ${ }^{4}$ Department of Surgery, Kyoto University Graduate School of Medicine, Kyoto, Japan. ${ }^{5}$ Department of Nephrology, Kyoto University Graduate School of Medicine, Kyoto, Japan. ${ }^{6}$ Department of Clinical Application, Center for iPS Cell Research and Application, Kyoto University, Kyoto, Japan. ${ }^{7}$ Department of Pharmacology, Kyoto University Graduate School of Medicine, Kyoto, Japan.

Correspondence should be addressed to H.S. (seno@kuhp.kyoto-u.ac.jp)

\section{Supplementary information list}

Supplementary Figures 1-16

Supplementary Table

Supplementary Reference 


\section{Supplementary Figures}
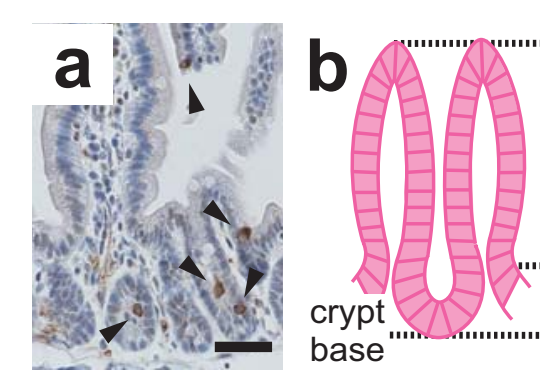

base"
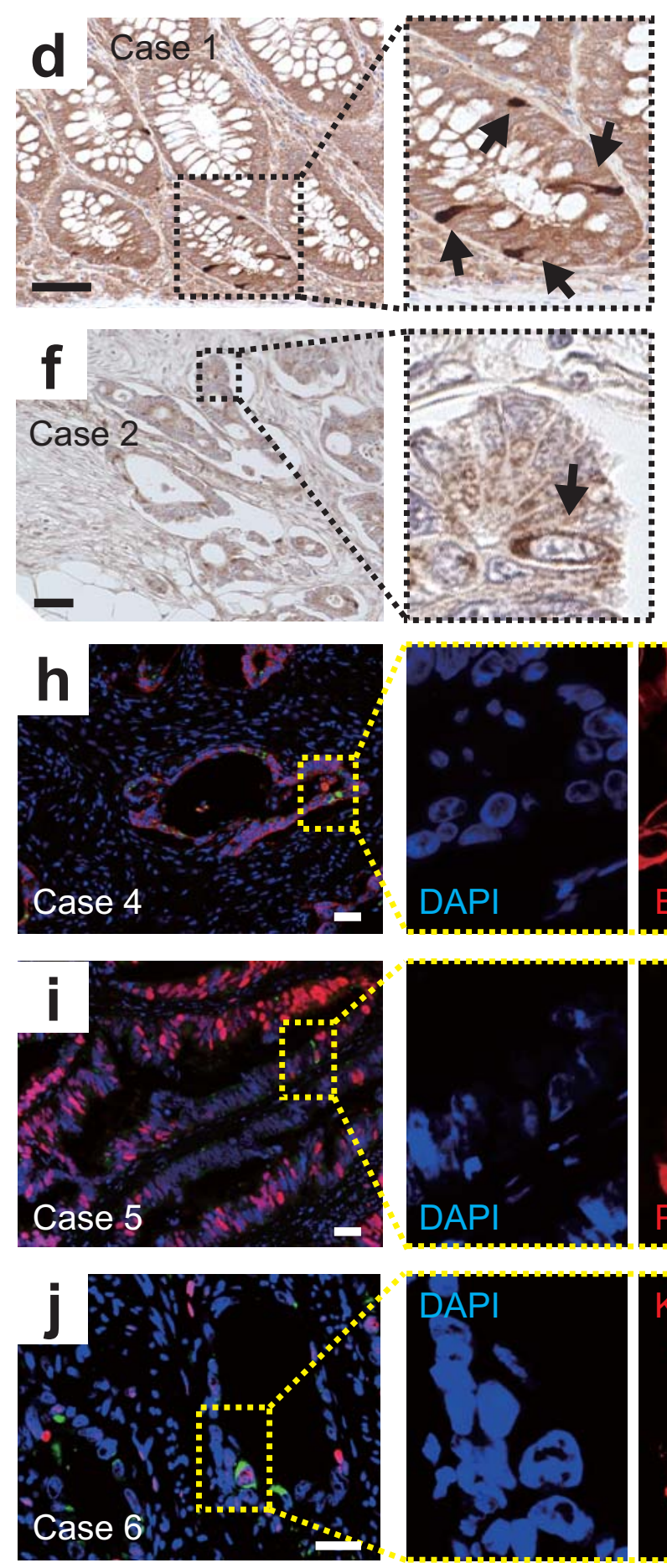
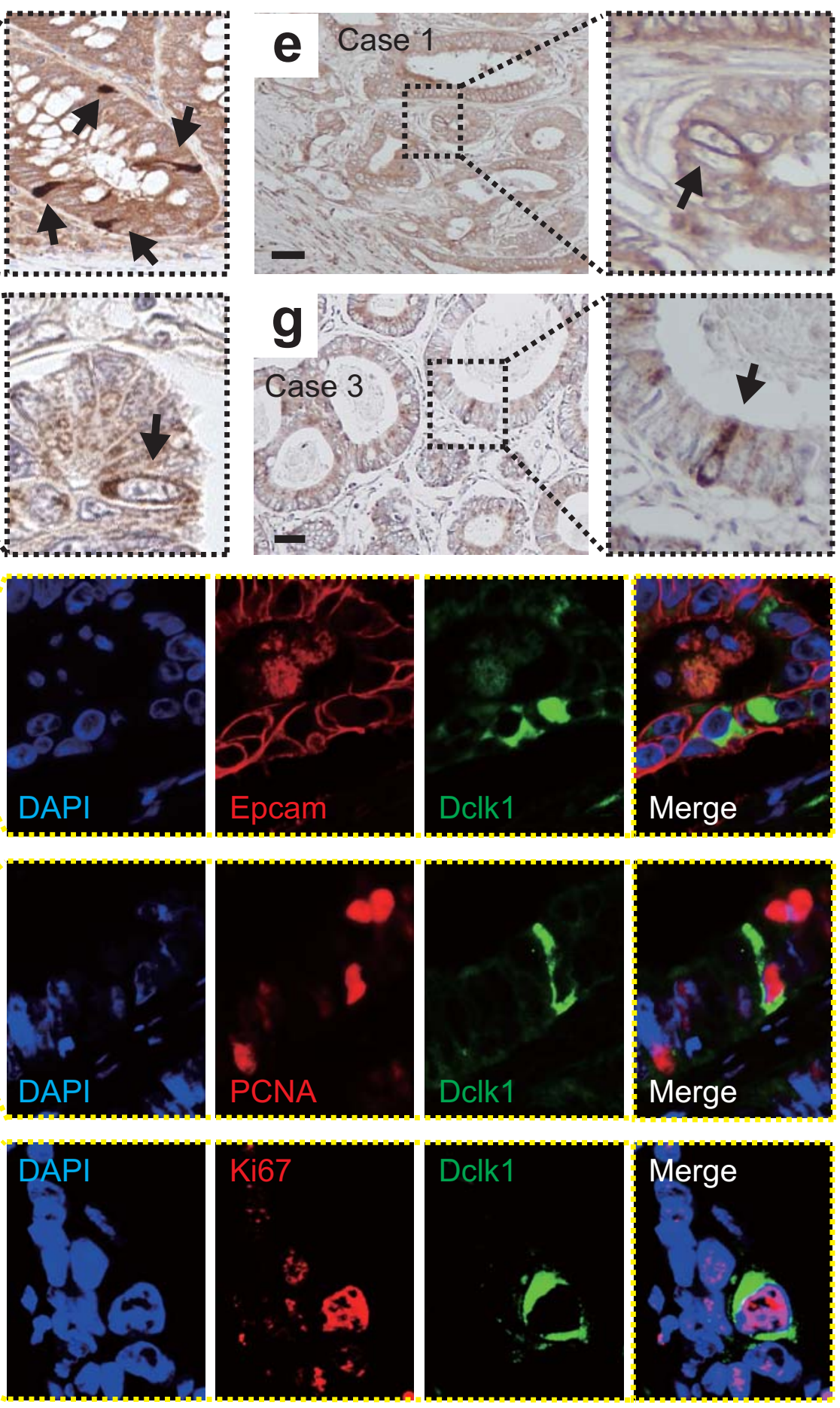


\section{Supplementary Figure 1. Immunohistochemical analyses of Dclk1 expression} in mice and humans. (a) Immunohistochemistry of Dclk1in murine normal small intestine. Dclk $1^{+}$cells (black arrowheads) were observed in both the crypts and villi. (b) The number and localization of Dclk1-stained cells per 1000 crypt-villus units showed Dclk $1^{+}$cells were observed most frequently at the lower crypt $(n=3)$. Crypt-villus junction (CVJ) indicated the boundary between the higher crypt and the villus. (c) Immunohistochemistry of Dclk1 in the polyps of $A p c^{\mathrm{Min} /+}$ mice. The black dotted box shows a magnified view of Dclk $1^{+}$tumor cells. (d-j) Six representative cases of human CRCs stained with Dclk1 (d-j). The expression of Dclk1 was observed in both human normal colonic crypts (d) and CRCs (e-g). The black dotted boxes show magnified views of Dclk $1^{+}$cells (black arrows). The proportion of Dclk $1^{+}$cancer cells was determined in 10 randomly selected high power fields $(\times 400)$ for each sample, and the frequency of Dclk $1^{+}$cells in CRC specimens ranged from approximately 1 per $2 \times 10^{2}$ to 1 per $5 \times 10^{3}$. Double immunostaining of Dclk1 (green) and Epcam (red) showed that Dclk1 was expressed in cancer cells (h). Dclk $1^{+}$cancer cells (green) occasionally expressed the proliferation markers PCNA (i, red) or Ki67 (j, red). The yellow dotted boxes show magnified views of overlapping cells. Bars, $50 \mu \mathrm{m}$. 
a

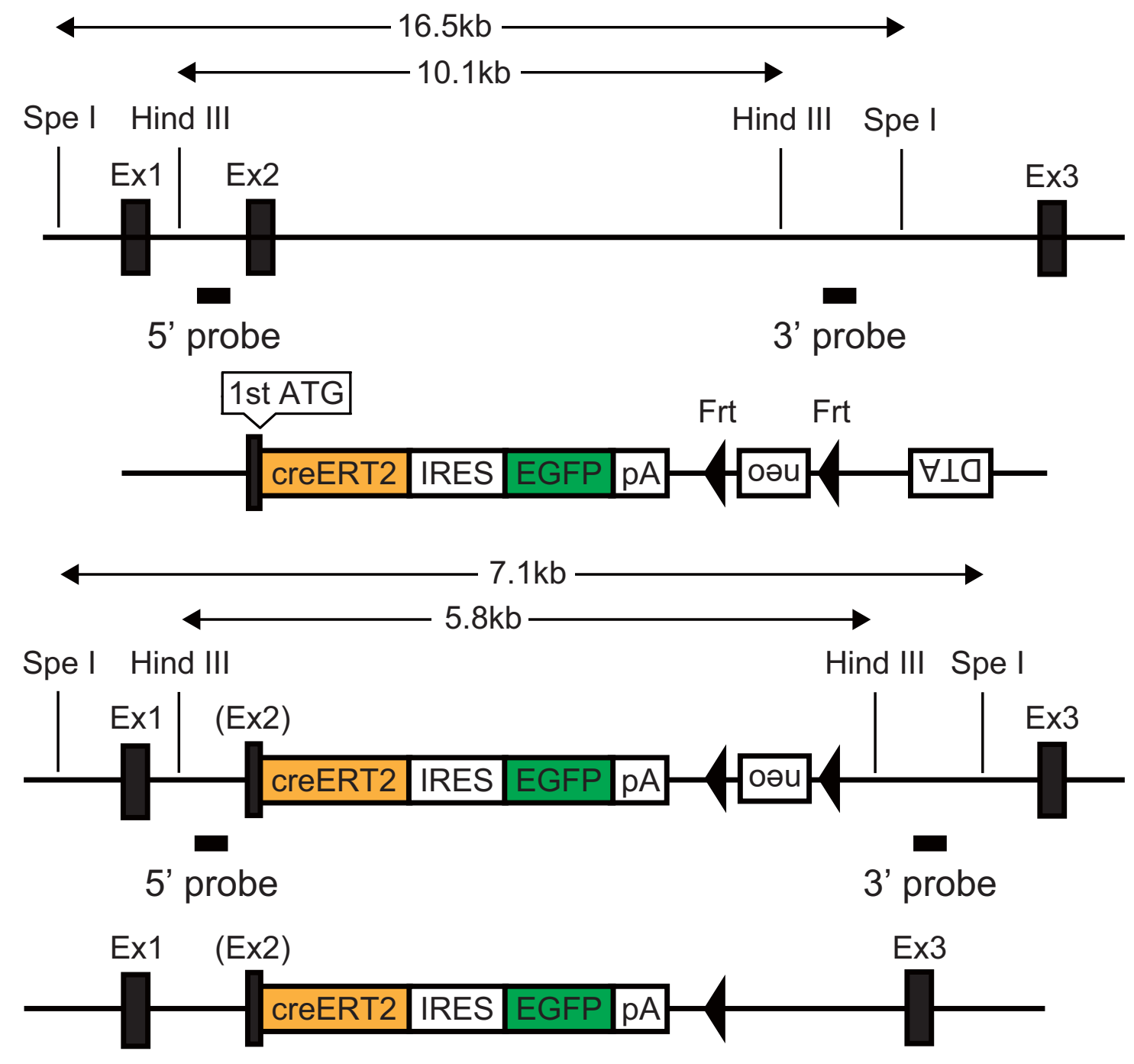

(Flp-mediated excision)

b

$\frac{5 \text { ' probe }}{\text { WT KI }}$

$10.1 \mathrm{~kb}$

$\frac{\text { 3' probe }}{\text { WT KI }}$

$16.5 \mathrm{~kb}$

C

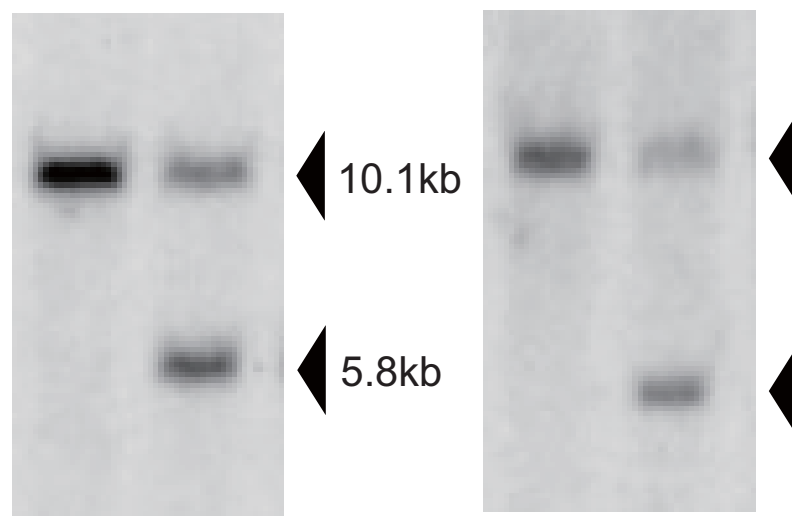

$7.1 \mathrm{~kb}$
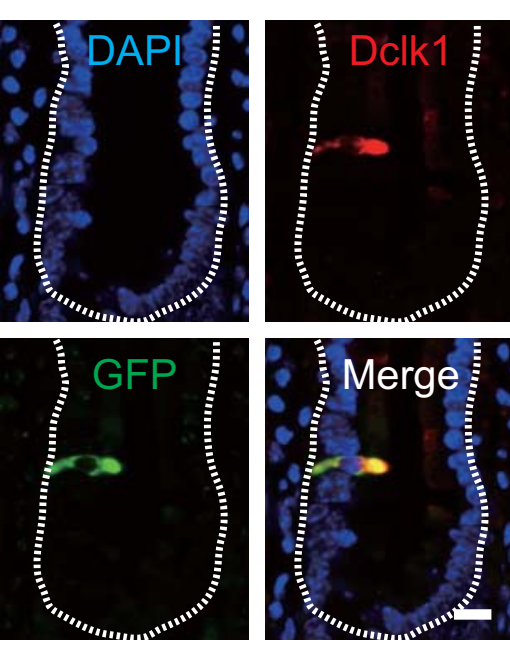
Supplementary Figure 2. Generation of Dclk1-creERT2-IRES-EGFP mice. (a) A creERT2-IRES-EGFP cassette was cloned into the first ATG site in exon 2 of the mouse Dclk1 gene. The expression construct was linearized and transfected into C57/BL6 mouse embryonic stem (ES) cells by electroporation, and neomycin-resistant recombinant ES clones were selected. DNA from all clones was screened for correct targeting by PCR with primers flanking the $5^{\prime}$ short arm (not shown). All positive clones and randomly selected negative clones were then confirmed by Southern blotting using the $5^{\prime}$ and $3^{\prime}$ probes. The neomycin selection cassette was later excised in vivo by crossing with FLP mice. Efficient cre expression was given priority, while several splice variants of Dclk1 that may compensate for the function of Dclk1 remained in Dclk1-creERT2-IRES-EGFP $\left(D c l k 1^{c r e E R T 2 /+}\right)$ mice ${ }^{33,34}$. (b) Representative Southern blotting using the $5^{\prime}$ and $3^{\prime}$ probes. (c) Immunofluorescent staining demonstrated GFP (green) strictly colocalized with anti-Dclk1 staining (red) in Dclk $1^{\text {creERT2/+ }}$ mice. Bars, $10 \mu \mathrm{m}$. 


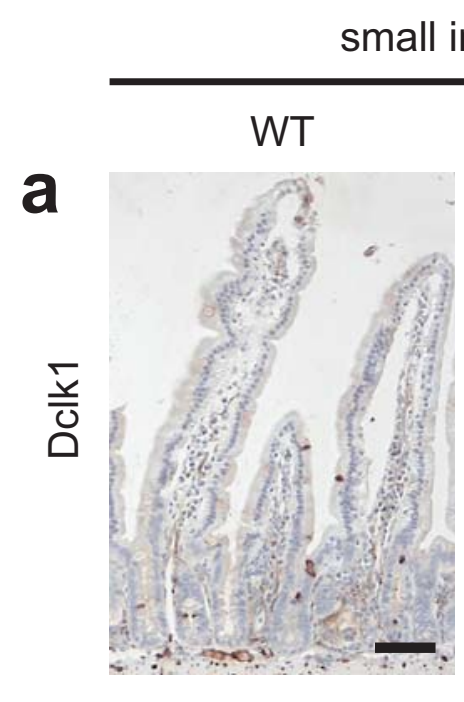

colon

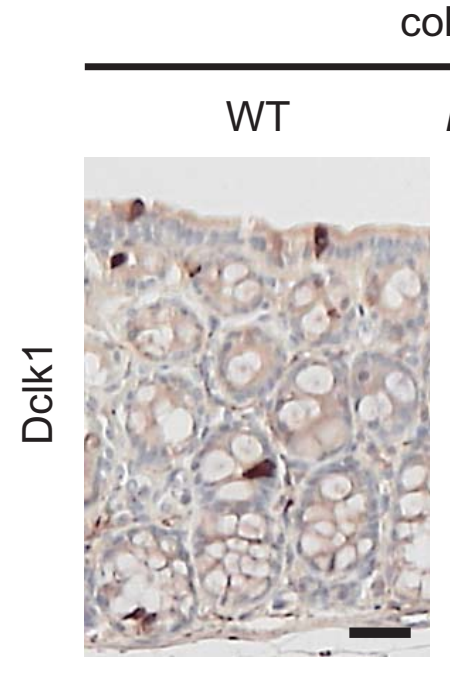

Dclk1 creERT2/creERT2
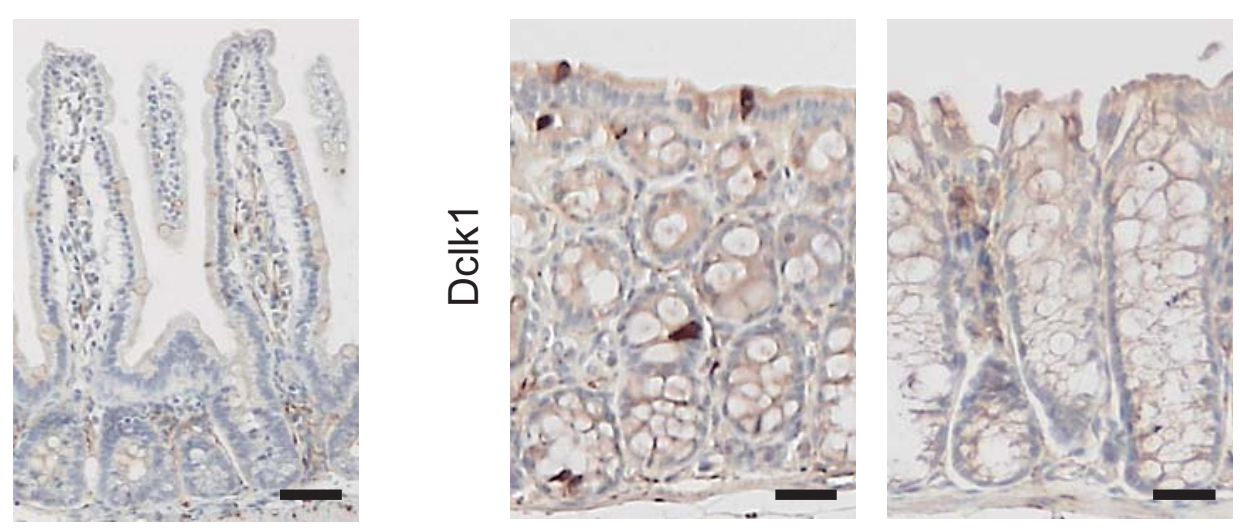

small intestine

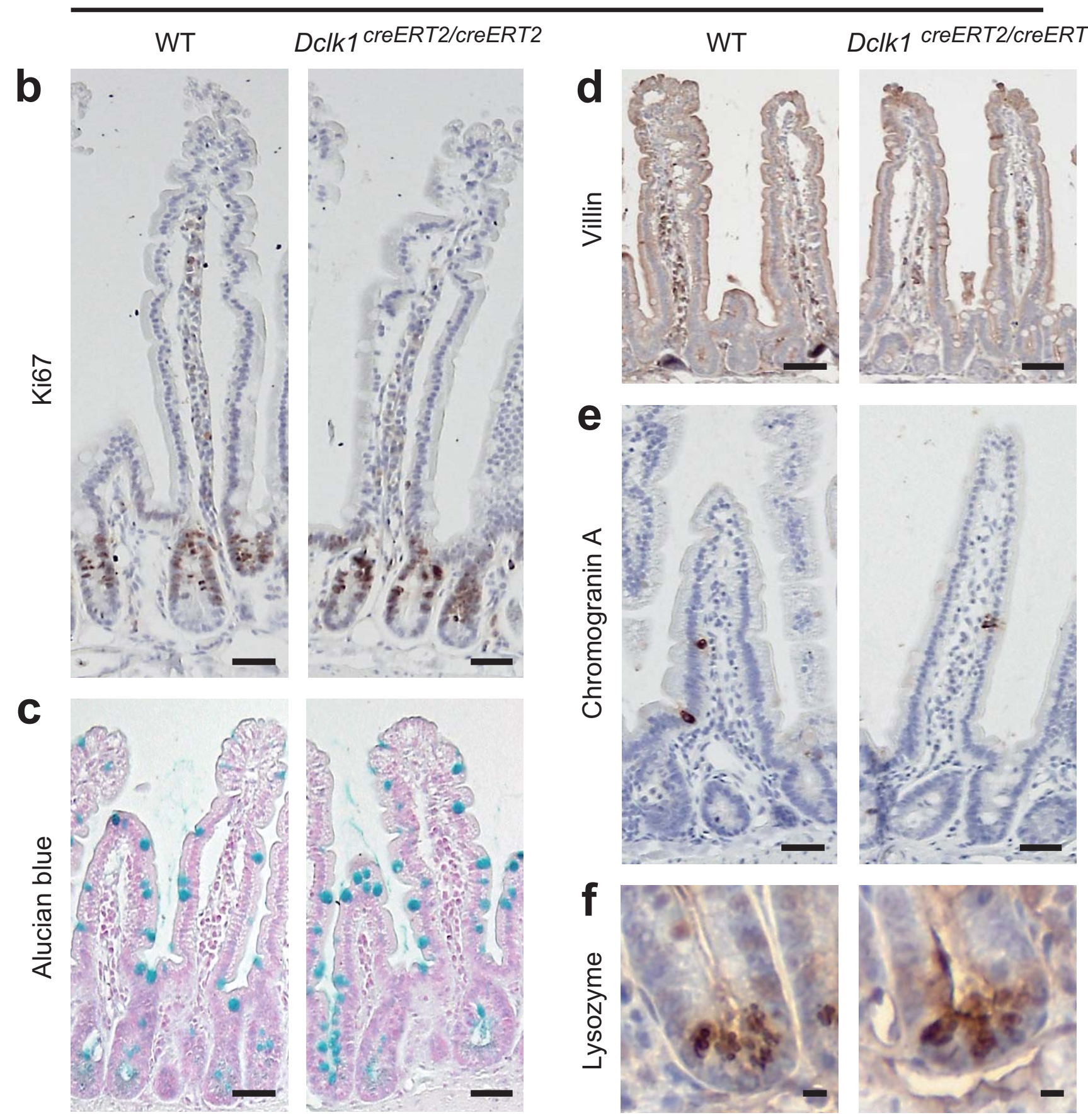


Supplementary Figure 3. Dclk1 ${ }^{\text {creERT2/creERT2 }}$ mice showed no difference in the intestinal structure compared with wild-type mice. (a) Immunohistochemistry for Dclk1 in the small intestine (left) and colon (right) of wild-type (WT) and

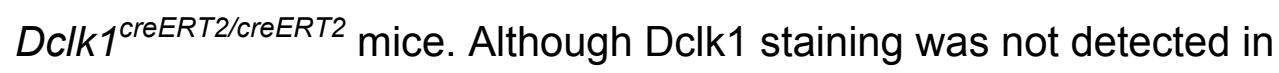

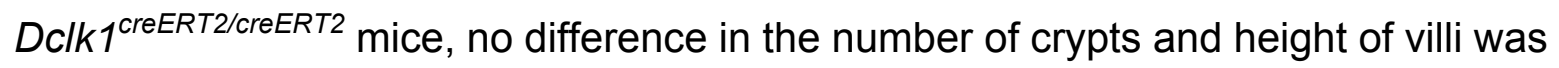
shown compared with WT mice. (b) Immunohistochemistry for Ki67 showed no

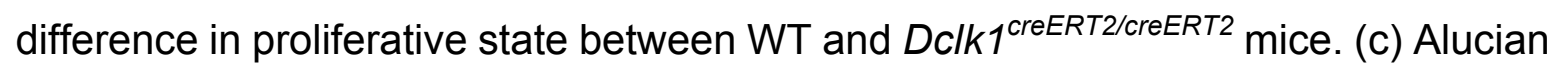
blue staining showed no difference in the number of goblet cells between WT and $D c / k 1^{\text {creERT2/creERT2 }}$ mice. (d-f) Immunohistochemistry for villin (d), chromogranin A (e), and lysozyme (f) demonstrated no difference in the number of enterocytes,

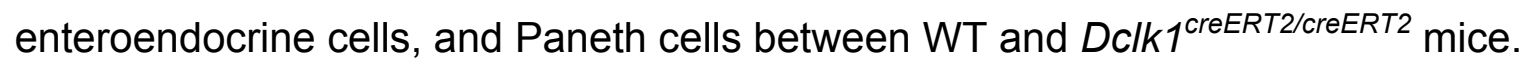
Bars, $50 \mu \mathrm{m}(\mathrm{a}-\mathrm{e})$ and $10 \mu \mathrm{m}(\mathrm{f})$. 

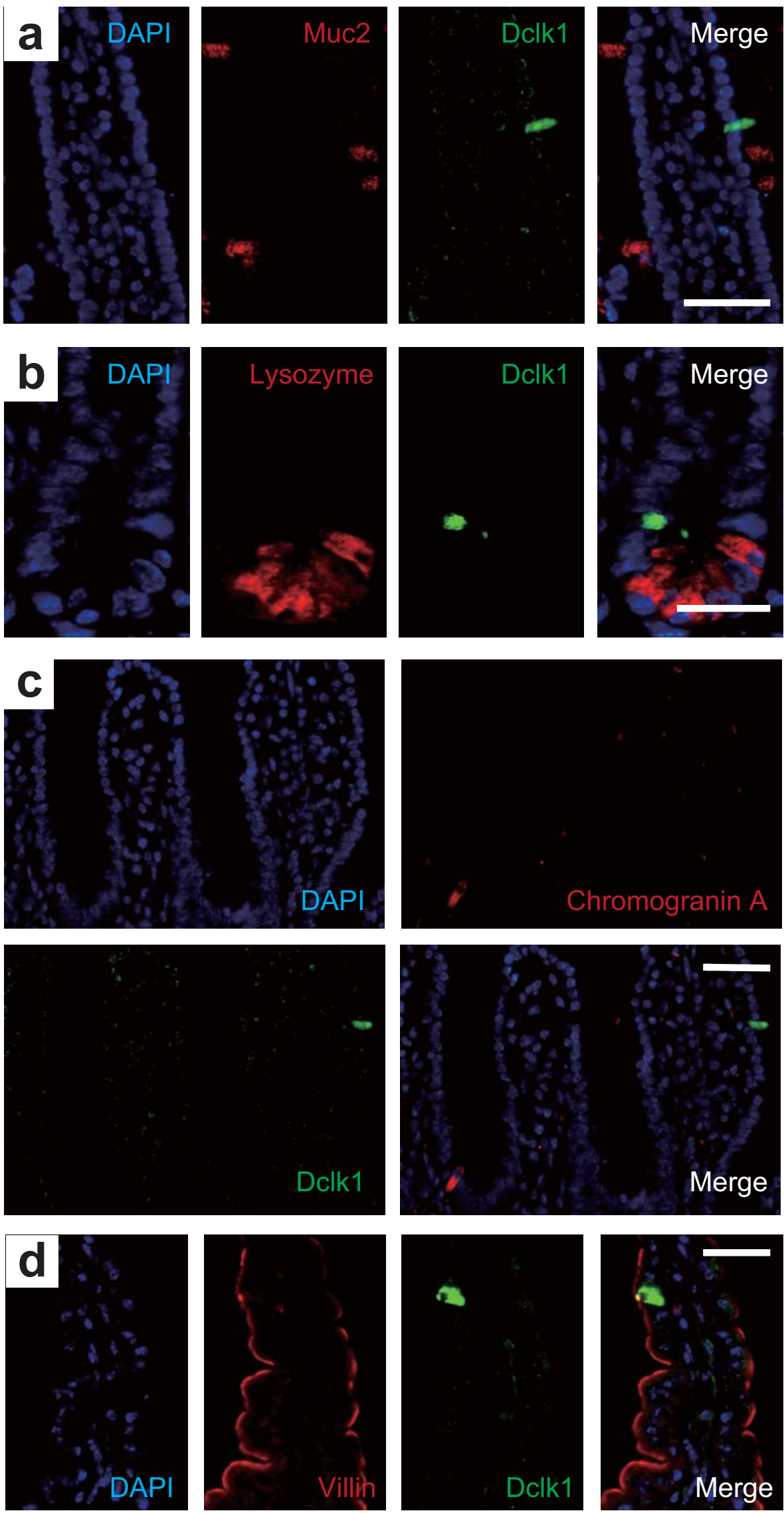


\section{Supplementary Figure 4. Dclk1 ${ }^{+}$cells were different from other differentiated} cells in the intestine. (a-d) Double-staining against Dclk1 (GFP) and other differentiated cell markers (Muc2, lysozyme, chromogranin A, and villin) in $D c / k 1^{\text {creERT2/+ }}$ mice are shown. Dclk1 (GFP, green) ${ }^{+}$cells were different from Muc2-positive goblet cells (a, red), lysozyme-positive Paneth cells (b, red), and chromogranin A-positive enteroendocrine cells (c, red). Dclk1 (GFP, green) ${ }^{+}$cells showed stronger immunoreactivity toward villin (red) compared with enterocytes (d). Bars, $50 \mu \mathrm{m}$. 

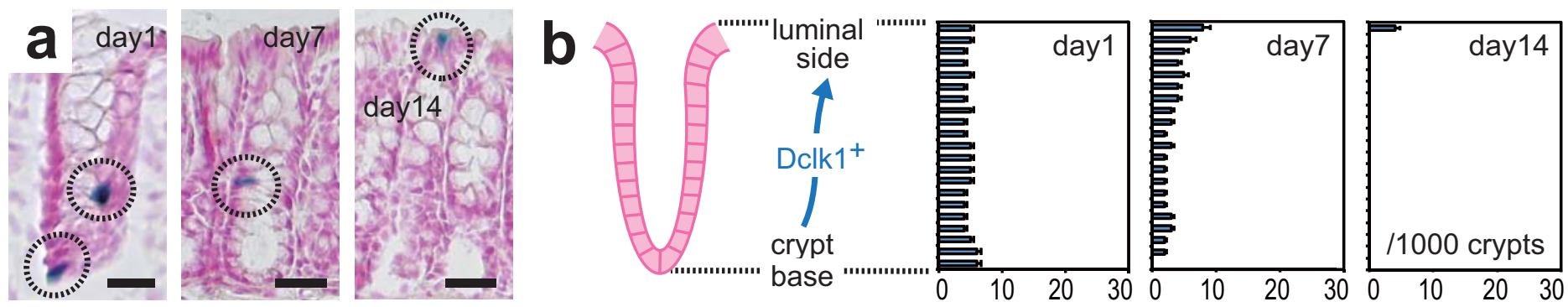

Supplementary Figure 5. Cre-mediated cell tracking of Dclk1+ cells in normal colon. (a)

Representative LacZ staining (black dotted circles) against colon of Dclk1 ${ }^{\text {creERT2/+; }}$ Rosa26R mice on days 1, 7, and 14 after a single tamoxifen injection. Bars, $50 \mu \mathrm{m}$. (b) Number and localization of blue-labeled Dclk $1^{+}$cells per 1000 crypts after a single tamoxifen injection ( $n=3$ for each time point). 


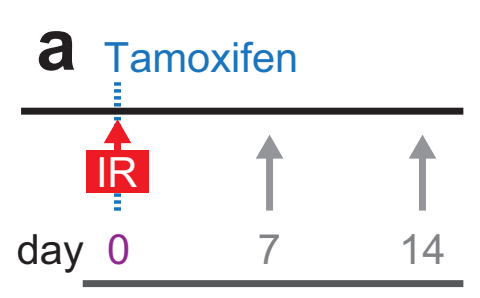

analysis

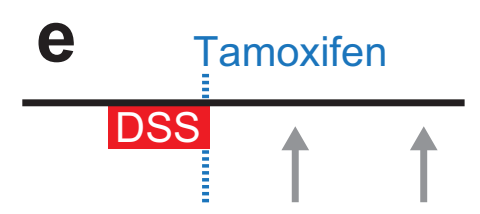
day 0

$\begin{array}{lll}7 & 10 \quad 14 \\ \text { analysis }\end{array}$

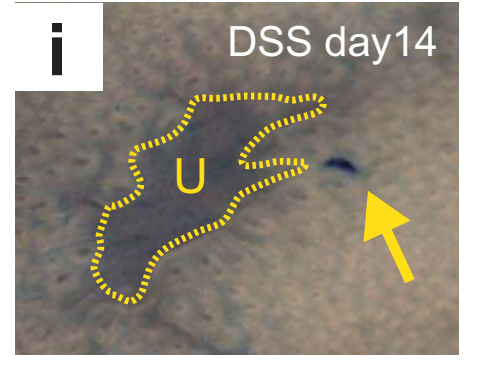

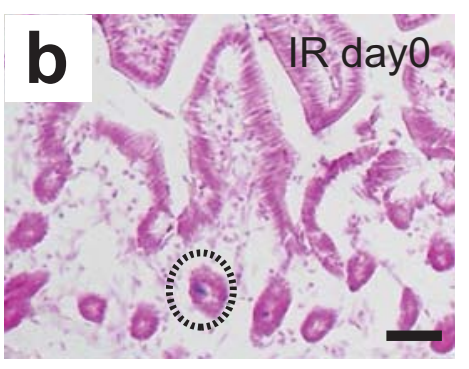
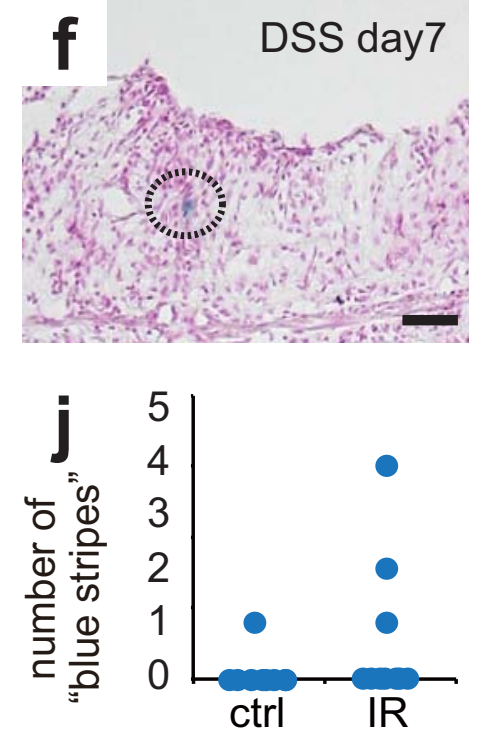
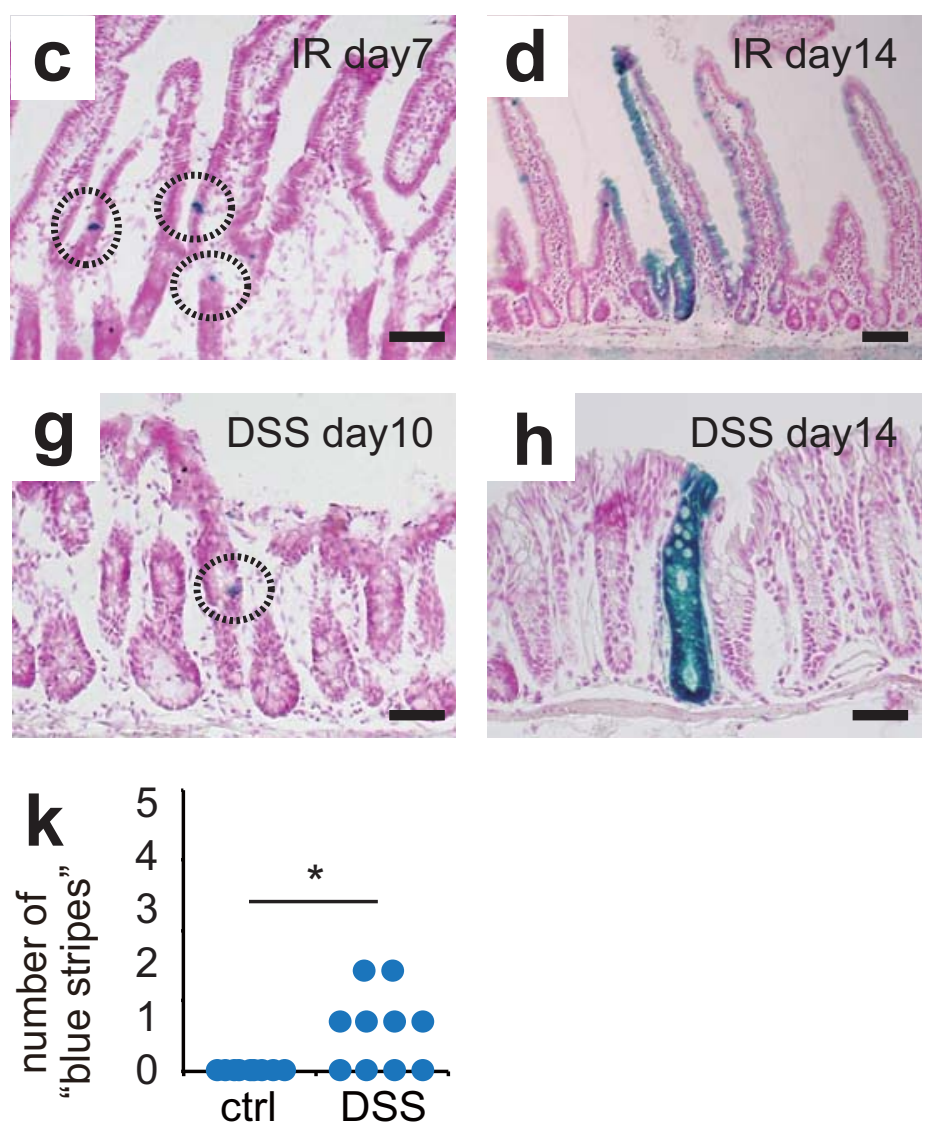

Supplementary Figure 6. Dclk1+ cells rarely showed stemness, even during regeneration after mucosal injury. (a) Treatment schedule of irradiation (IR)-induced mucosal injury.

$D c / k 1^{\text {creERT2/+; }}$ Rosa26R mice were treated with $8 \mathrm{~Gy} \mathrm{IR}$ on day 0 , and the small intestine analyzed on days 0 ( $6 \mathrm{~h}$ after IR), 7 , and 14. (b-d) Blue-labeled Dclk1+ cells (black dotted circles) were detected on days 0 (b) and 7 (c). On day 14, extremely small proportion of "blue stripes" was detected (d). (e) Treatment schedule of dextran sulfate sodium (DSS)-induced mucosal injury. Dclk1 ${ }^{\text {creERT2/+; }}$ Rosa26R mice were treated with $2.0 \%$ DSS from days $0-7$, and colons analyzed on days 7 (immediately after final DSS), 10, and 14. (f-i) Blue-labeled Dclk $1^{+}$cells (black dotted circles) were detected on days 7 (f) and $10(\mathrm{~g})$, and blue stripes were rarely detected adjacent to the ulcer $(\mathrm{U})$ on day 14 (h, i, yellow arrow). (j) The number of blue stripes was counted in the whole intestine of untreated (ctrl) and IR-treated mice (IR; $n=10)$. (k) The number of blue stripes was significantly larger in the whole colon of DSS-treated mice (DSS; $n=10$ ) than in that of control mice. ${ }^{*} P<0.05$. Bars, $50 \mu \mathrm{m}$. 


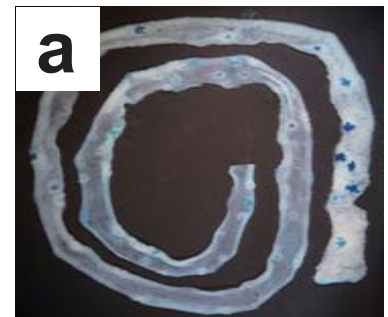

small intestine

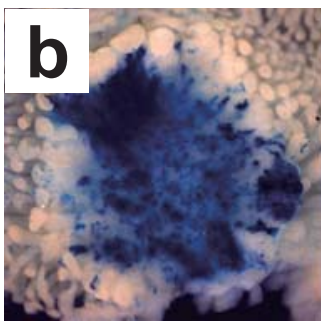

duodenum

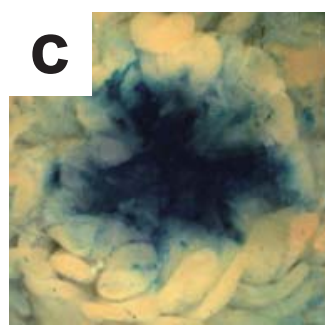

jejunum

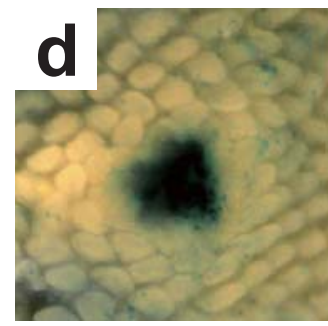

ileum

Supplementary Figure 7. Dclk1+ tumor cells generated "blue polyps" in whole small intestine. (a) Macroscopic images of blue polyps in whole small intestine of $D c / k 1^{\text {creERT2/+; }}$ Rosa26R; $A p c^{\text {Min/+ }}$ mice on day 7 after tamoxifen induction. "Blue polyps" were observed throughout the small intestine, although most abundant in the duodenum. (b-d) Representative magnified images of blue polyps in the duodenum (b), jejunum (c), and ileum (d). 

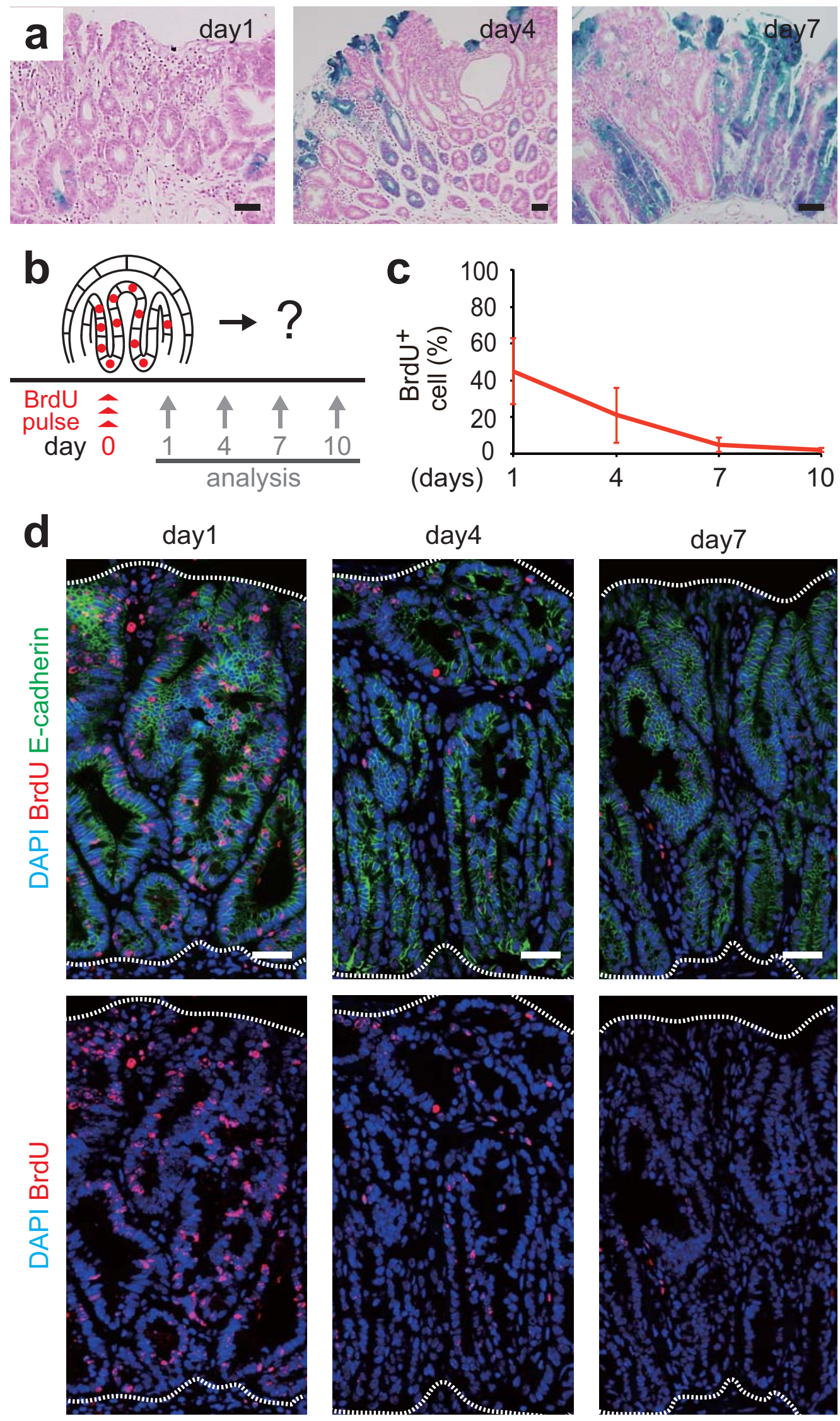


\section{Supplementary Figure 8. The turnover rate of tumor cells was approximately}

7 days. (a) Representative LacZ staining on days 1, 4, and 7 after a single tamoxifen injection in the polyps of $L g r 5^{\text {creERT2/+ }}$; Rosa26R; $A p c^{\mathrm{Min} /+}$ mice. Descendant tumor cells from Lgr $5^{+}$cells occupied the whole polyp within 7 days. Uniformly-labeled blue polyps were rarely observed in $\operatorname{Lgr} 5^{\text {creERT2/+ }}$; Rosa26R; $\mathrm{Apc}^{\mathrm{Min} / \mathrm{+}}$ mice, because IRES sequence between $\operatorname{Lgr} 5$ promoter and creERT2 may lower the expression efficiency of creERT2 in $L g r 5^{\text {creERT2/+ }}$ mice. (b) Treatment schedule for BrdU pulse and chase. Apc ${ }^{\mathrm{Min} /+}$ mice were treated with BrdU 3 times a day and the polyps were analyzed by immunohistochemistry of BrdU on days 1, 4, 7, and 10 after the treatment. (c) The number of BrdU-labeled tumor epithelial cells was counted in the polyps at each time point $(n=3)$. The proportion decreased rapidly and $>95 \%$ of $\mathrm{BrdU}^{+}$tumor epithelial cells disappeared after 7 days chase. (d) Representative immunofluorescent staining of BrdU (red) in the polyps on days 1, 4, and 7. E-cadherin (green) was used for counter-staining to identify tumor epithelia. Bars, $50 \mu \mathrm{m}$. 

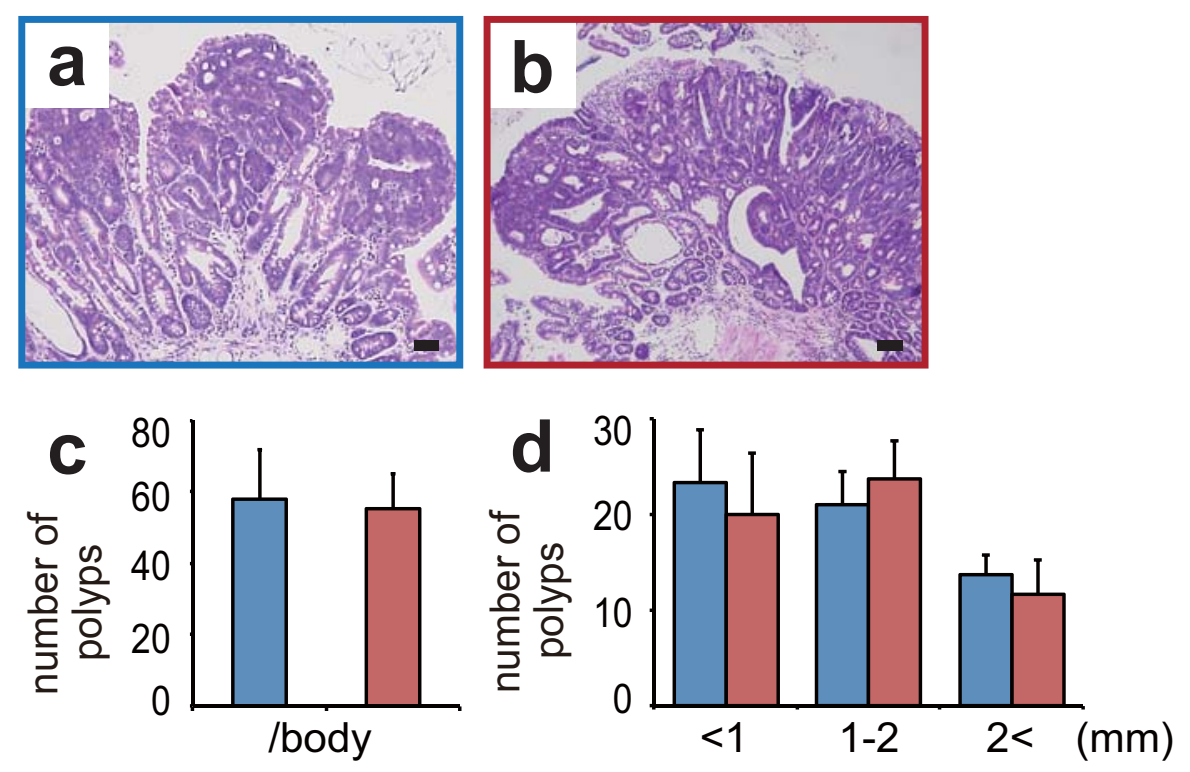

Apc $\mathrm{Min} /+^{\mathrm{a}} \square$ Apc $^{\mathrm{Min} /+} ;$ Dclk1 ${ }^{\text {creERT2/creERT2 }}$

Supplementary Figure 9. $A p c^{\mathrm{Min} /+} ; D c / k 1^{\text {creERT2/creERT2 mice }}$ showed no difference in the number and size of polyps compared with $A p c^{\mathrm{Min} / \mathrm{t}}$ mice. (a, b) Representative $\mathrm{H} \& \mathrm{E}$ staining of small intestinal polyps of $\mathrm{Apc}^{\mathrm{Min/+}}(\mathrm{a})$ and $A p c^{\text {Min/+ }} ; D c l k 1^{\text {creERT2/creERT2 }}$ (b) mice. (c) There was no difference in the total number of small intestinal polyps between $A p c^{\mathrm{Min/} / \mathrm{t}}$ mice and $A p c^{\mathrm{Min} /+} ; D c l k 1^{\text {creERT2/creERT2 }}$ mice. (d) The number of small intestinal polyps in $A p c^{\mathrm{Min} / \mathrm{t}}$ mice and $A p c^{\mathrm{Min/} / *} ; D c / k 1^{\text {creERT2/creERT2 }}$ mice was counted by polyp size fraction. No significant difference was observed between these mice, which seemed to be different from a previous report in which Dclk1 knockdown resulted in tumor regression in vitro ${ }^{35}$. This might be due to Dclk1 splice variants remaining in the Dclk1-creERT2 knock-in allele and homologues of $D c / k 1$ which can compensate for the function of Dclk1 (see also Supplementary Figure 2). Bars, $50 \mu \mathrm{m}$. 

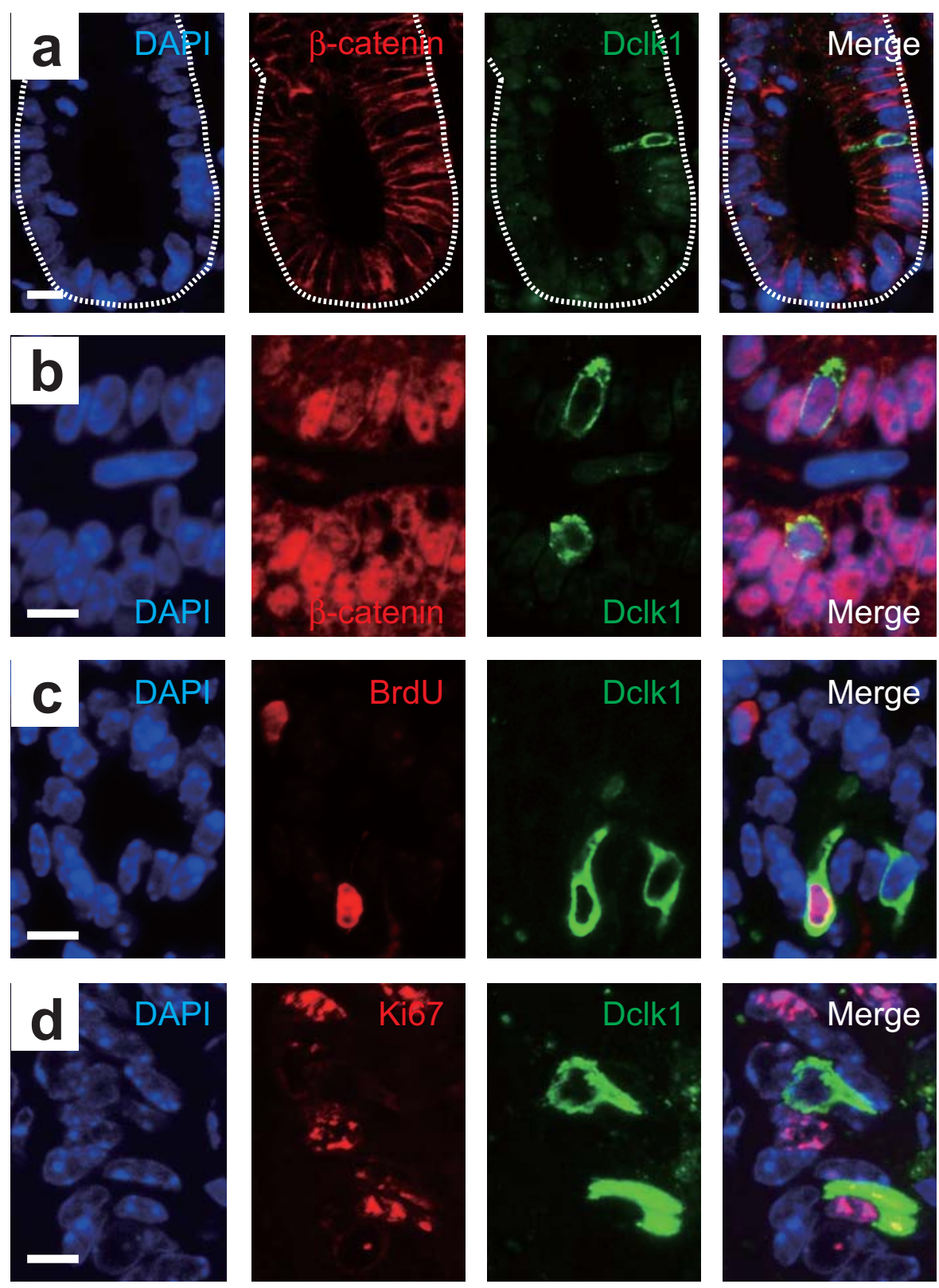

Supplementary Figure 10. Dclk1+ tumor cells occasionally expressed proliferation markers in the polyps of $A p c^{M i n /+}$ mice.

(a) Double-immunostaining demonstrated that Dclk1 ${ }^{+}$cells (green) did not colocalize with nuclear $\beta$-catenin staining (red) in the normal intestine. (b) Nuclear $\beta$-catenin (red) was detected in most Dclk1+ tumor cells (green) in the polyps of $A p c^{\mathrm{Min} /+}$ mice. (c, d) Dclk1+ tumor cells (green) occasionally colocalized with BrdU (c) and Ki67 (d) in the polyps of $\mathrm{ApC}^{\mathrm{Min} / \mathrm{t}}$ mice. Bars, $10 \mu \mathrm{m}$. 

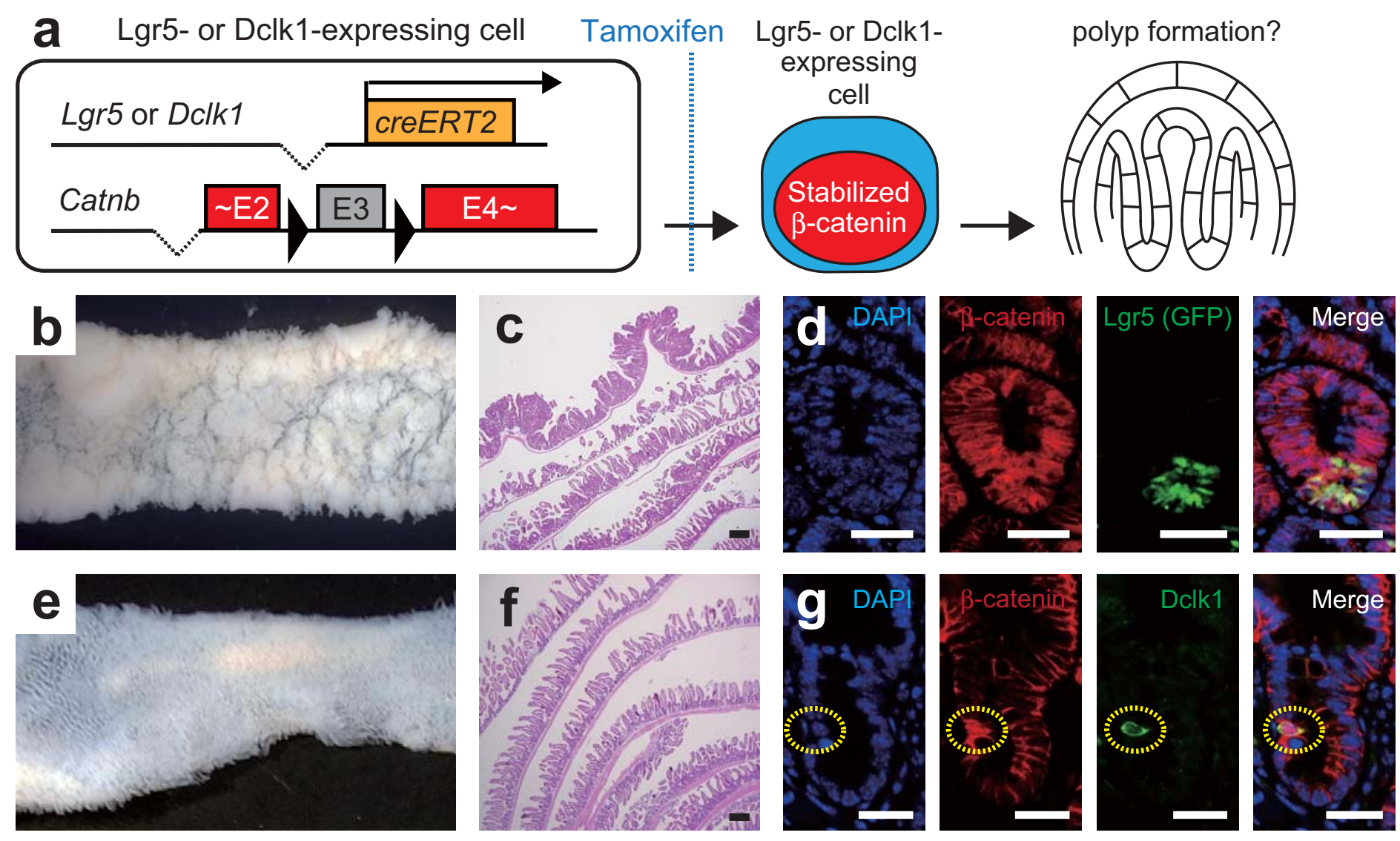

\section{Supplementary Figure 11. Induced stabilization of $\beta$-catenin in Dclk1+ cells did not cause} polyp formation. (a) Experimental strategy of tamoxifen-inducible Cre-mediated stabilization of

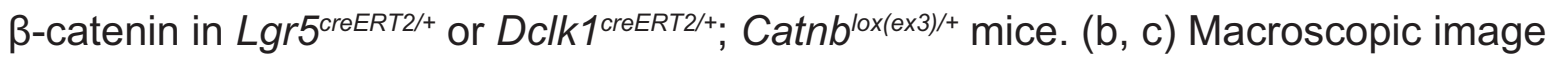

(b) and histology (c) of small intestine in Lgr5 ${ }^{\text {creERT2/+; }}$ Catnb ${ }^{\operatorname{lox}(e \times 3) /+}$ mice showed development of numerous polyps 40 days after tamoxifen injection. (d) Immunofluorescent staining of Lgr5 (GFP, green) and $\beta$-catenin (red) in the polyps of $L g r 5^{\text {creERT2/+; }}$ Catnh ${ }^{\text {lox(ex3)/+ }}$ mice 40 days after injection. Lgr5+ tumor cells positive for nuclear $\beta$-catenin were observed at the polyp base. (e, $f$ ) Macroscopic image (e) and histology (f) showed no detectable polyp in the small intestine of Dclk $1^{\text {creERT2/+; }}$ Catnb ${ }^{\text {lox(ex3)//+ }}$ mice even 45 days after tamoxifen injection. (g) Two days after tamoxifen injection, Dclk1+ cells (green) showed nuclear accumulation of $\beta$-catenin (red) in the normal intestine of $D c / k 1^{\text {creERT2/+; }}$ Catnh $b^{\text {lox(ex3)/+ }}$ mice (yellow dotted circles). Bars, $50 \mu \mathrm{m}$. 

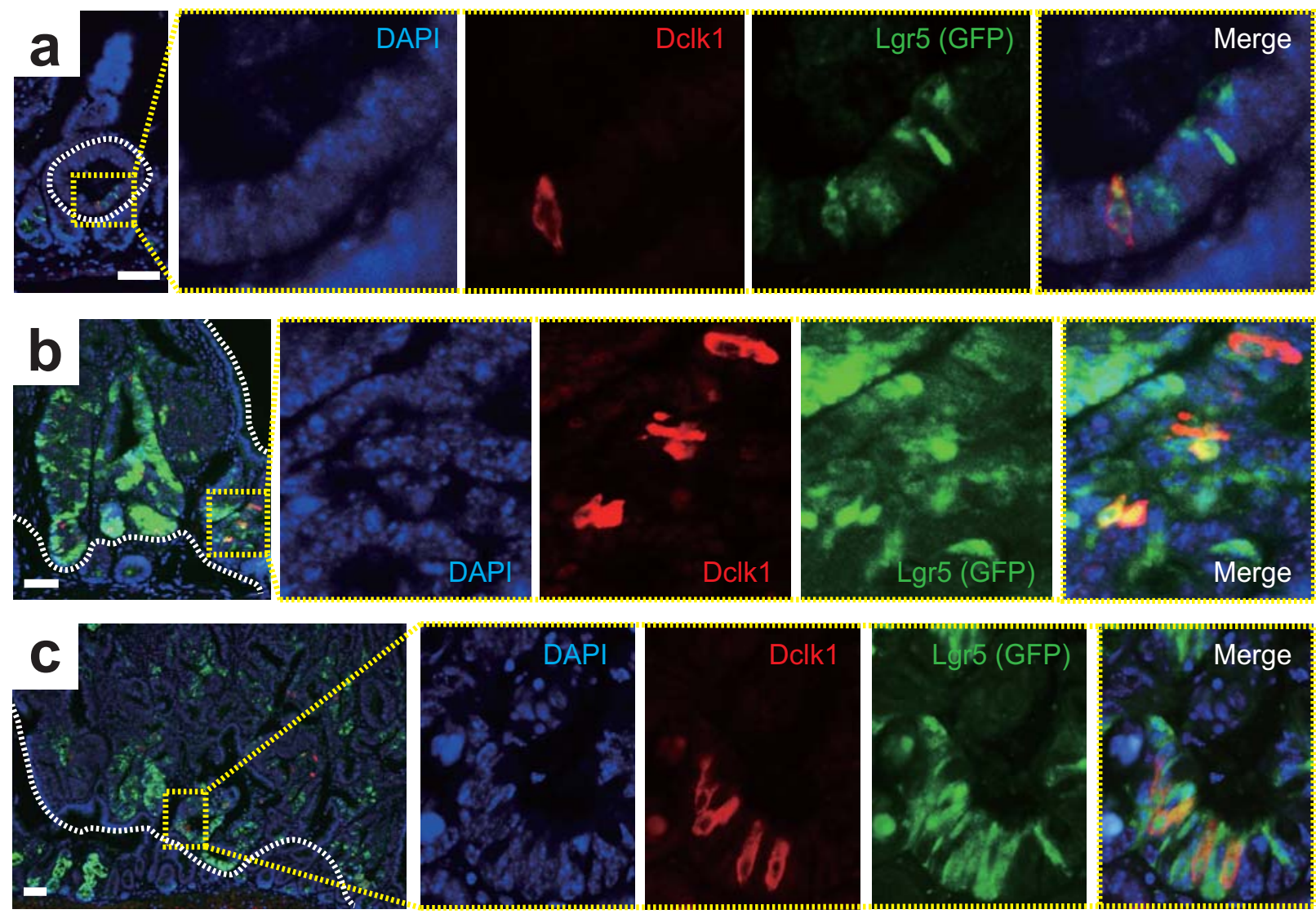

\section{Supplementary Figure 12. Dclk1+/Lgr5 ${ }^{+}$cells were detected in the polyps of}

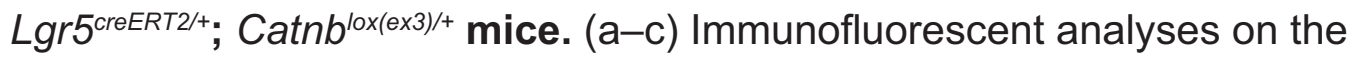
expression of Dclk1 (red) and Lgr5 (GFP, green) in Lgr5 ${ }^{\text {creeRT2/+; }}$ Catnb ${ }^{\text {lox(ex3)/+ }}$ mice. Yellow dotted boxes showed magnified images. Dclk1+//Lgr $5^{+}$tumor cells were detected at the base of small (a), middle (b), and large (c) polyps. Bars, $50 \mu \mathrm{m}$. 


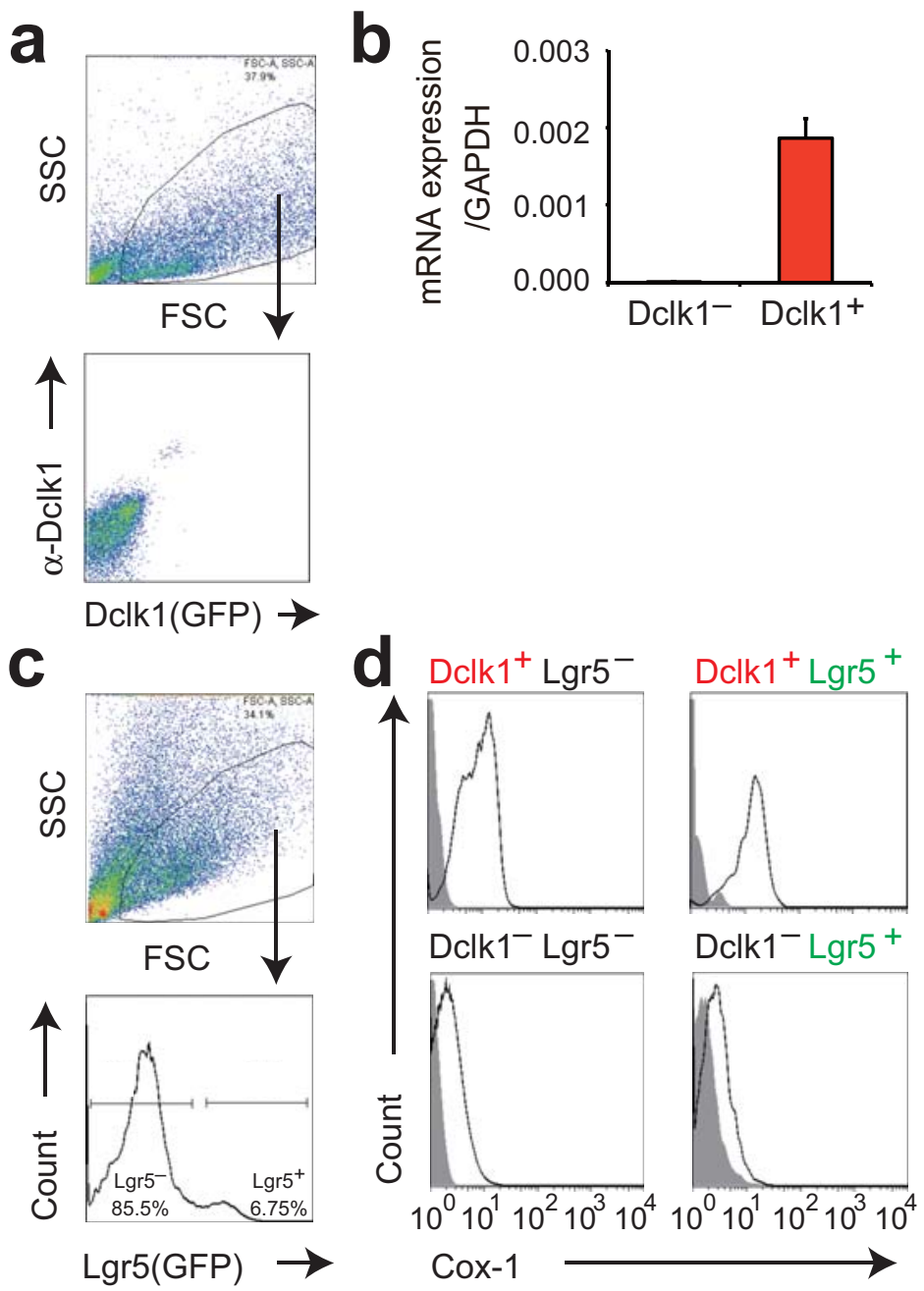

\section{Supplementary Figure 13. FACS analyses of intestinal} tumor cells on the basis of Dclk1 and Lgr5 expression.

(a) Flow cytometry sorted tumor cells on the basis of Dclk1 and GFP expression in Dclk $1^{\text {creERT2/+; }}$ Apc ${ }^{\mathrm{Min} /+}$ mice.

GFP strictly colocalized with anti-Dclk1 staining in the polyps.

(b) qRT-PCR demonstrated that mRNA expression of the sequence targeting the creERT2-IRES-EGFP cassette was restricted to Dclk1-GFP ${ }^{+}$cells. (c) Flow cytometry sorted tumor cells on the basis of Lgr5-GFP expression in Lgr5creERT2/+; Catnb $^{\text {lox(ex3)//+ }}$ mice 40 days after tamoxifen injection.

The sorted Lgr5-positive or -negative tumor cells were collected for immunocytostaining. (d) Flow cytometry showed that the expression of Cox-1 was elevated in each population of Dclk $1^{+}$fractions. 


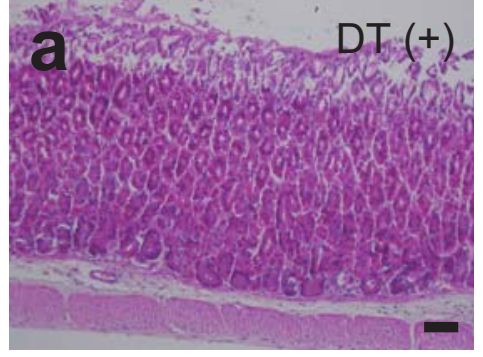

Stomach

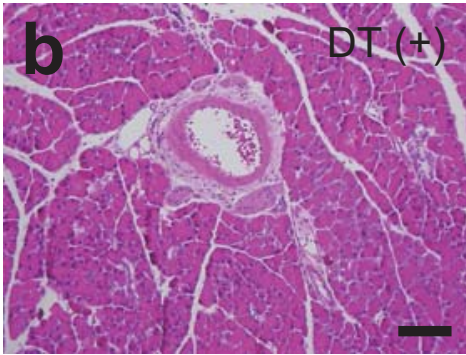

Pancreas

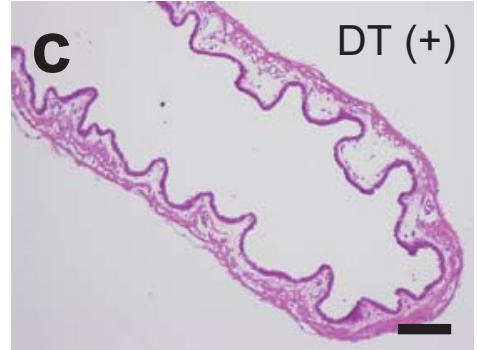

Gall bladder

Supplementary Figure 14. Intense ablation of Dclk1+ cells by multiple DT injection did not cause significant damage to other organs. $(a-c)$ Intense ablation of Dclk $1^{+}$cells by " 3 times daily for 3 days" injections of DT did not cause significant damage to the stomach (a), pancreas (b), or gallbladder (c)

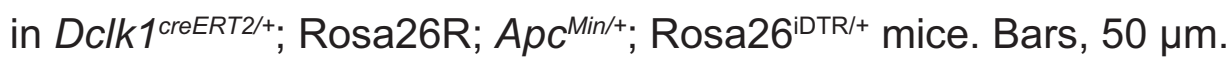



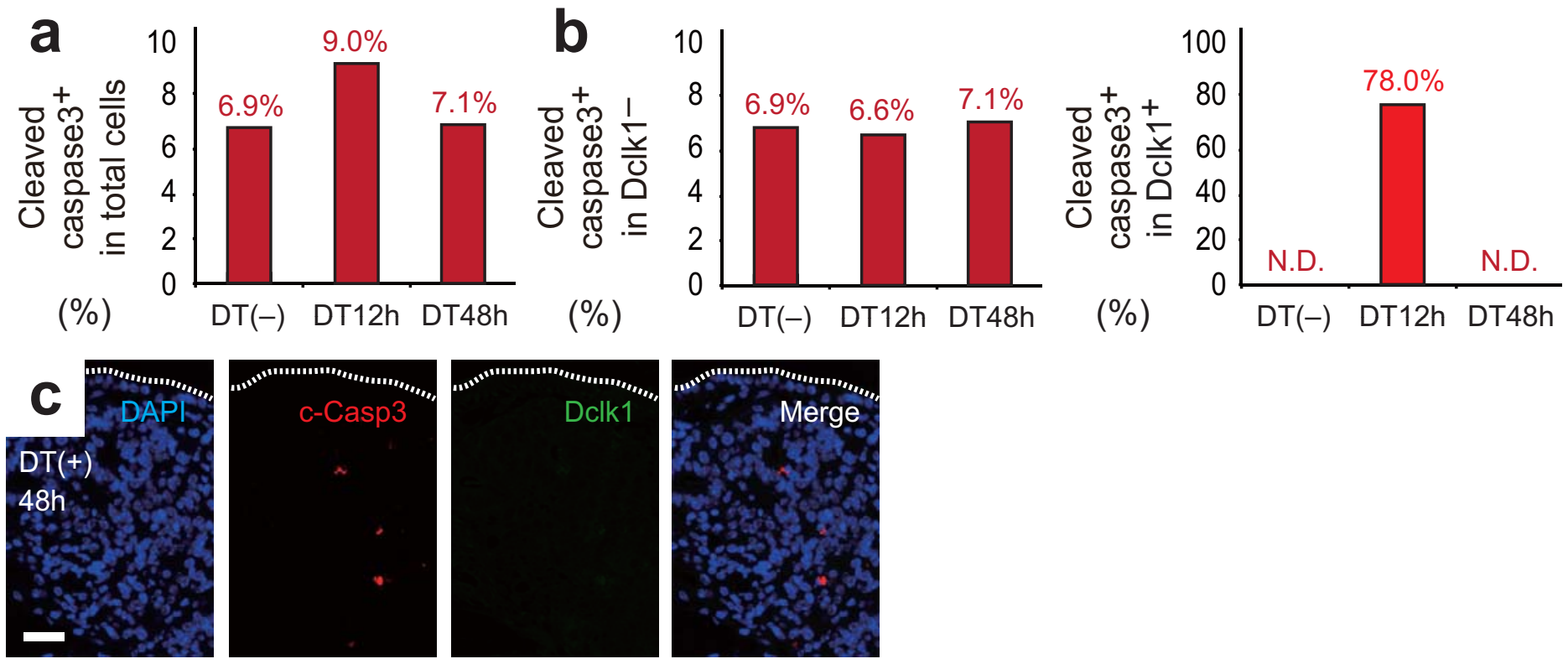

\section{Supplementary Figure 15. DT specifically killed Dclk1+ tumor cells without affecting the} apoptotic status of other tumor cells in the polyps. (a) The proportion of total cleaved caspase3positive apoptotic tumor cells in the untreated control polyps (DT(-)) and in the polyps at indicated time points (12 h and $48 \mathrm{~h}$ ) after DT injection of Dclk1 ${ }^{\text {creERT2/+; }}$ Rosa26R; Apc ${ }^{\mathrm{Min} /+}$; Rosa26 ${ }^{\mathrm{iDTR/+}}$ mice. Tamoxifen was injected $24 \mathrm{~h}$ before DT injection. The increase of the proportion of cleaved caspase3positive cells at early time point $\left(12 \mathrm{~h}\right.$ ) reflected the apoptosis of Dclk $1^{+}$cells (see panel b). (b) The proportion of apoptotic cells in Dclk1- tumor cells was not affected by DT treatment (left). On the other hand, the proportion of apoptotic cells in Dclk $1^{+}$tumor cells showed that most Dclk $1^{+}$tumor cells underwent apoptosis at early time point (12 h) after DT injection (right). Apoptotic Dclk $1^{+}$tumor cells were hardly detected at later time point (48 h). (c) Immunofluorescent staining of cleaved caspase 3 (red) and Dclk1 (GFP, green) $48 \mathrm{~h}$ after DT injection. Dclk1+ tumor cells were hardly detected in the collapsing polyps, suggesting that DT eliminated Dclk1 ${ }^{+}$tumor cells in early time points after DT injection. Bar, $50 \mu \mathrm{m}$. 

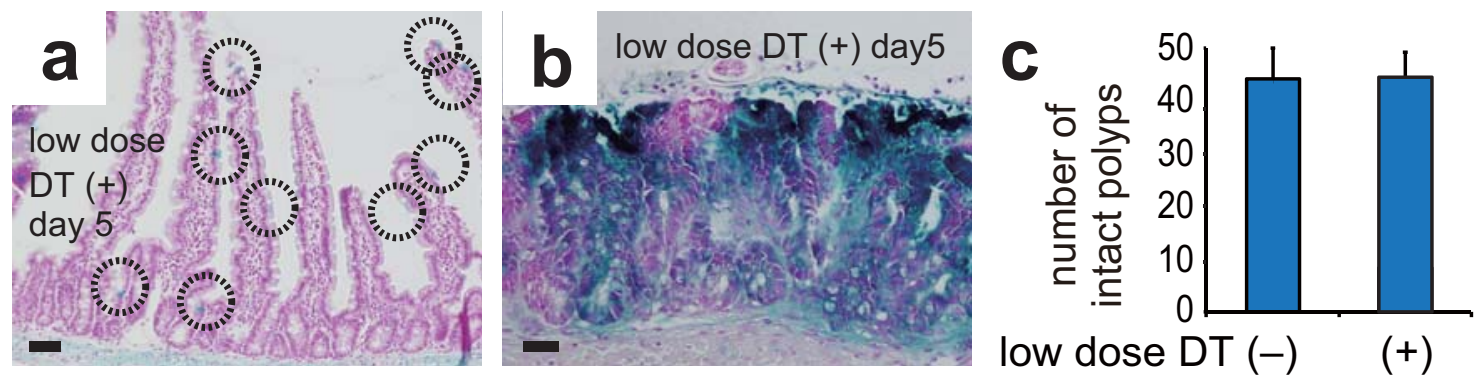

Supplementary Figure 16. Dclk1+ cells were not sufficiently eliminated by low-dose DT protocol. $(\mathrm{a}-\mathrm{c})$ To examine whether DT had a significant effect after the next day of the injection, low-dose (15 ng) DT was injected to Dclk1 $1^{\text {creERT2/+; }}$ Rosa26R; $A p c^{\text {Min/+; }}$ Rosa26 ${ }^{\text {iDTR/++ }}$ mice $24 \mathrm{~h}$ after tamoxifen administration, and mice were analyzed 5 days after low-dose DT injection $(n=5)$. Blue-labeled Dclk1+ cells (black dotted circles) were not significantly decreased by low-dose DT treatment (a). Fully labeled blue polyps could be detected in low-dose DT-treated mice (b). The number of the intact polyps was not decreased in low-dose DT-treated mice $(\mathrm{DT}(+))$ compared to untreated controls $(\mathrm{DT}(-))(\mathrm{c})$. Bars, $50 \mu \mathrm{m}$. 
Supplementary Table. Primers used in quantitative RT-PCR.

\begin{tabular}{|c|c|}
\hline Primer name & Sequence \\
\hline mouse GAPDH-Forward & 5'- AGGTCGGTGTGAACGGATTTG -3' \\
\hline mouse GAPDH-Reverse & 5'- TGTAGACCATGTAGTTGAGGTCA -3' \\
\hline sequence targeting creERT2-IRES-EGFP cassette-Forward & 5'- AGAACGGCATCAAGGTGAAC -3' \\
\hline sequence targeting creERT2-IRES-EGFP cassette-Reverse & 5'- TGCTCAGGTAGTGGTTGTCG -3' \\
\hline
\end{tabular}

\section{SUPPLEMENTARY REFERENCE}

33. Burgess, H.A. \& Reiner, O. Alternative splice variants of doublecortin-like kinase are differentially expressed and have different kinase activities. J Biol Chem 277, 17696-705 (2002).

34. Tuy, F.P., Saillour, Y., Kappeler, C., Chelly, J. \& Francis, F. Alternative transcripts of Dclk1 and Dclk2 and their expression in doublecortin knockout mice. Dev Neurosci 30, 171-86 (2008).

35. Sureban, S.M. et al. Selective blockade of DCAMKL-1 results in tumor growth arrest by a Let-7a MicroRNA-dependent mechanism.

Gastroenterology 137, 649-59, 659.e1-2 (2009). 